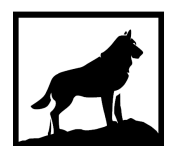

Michigan Technological

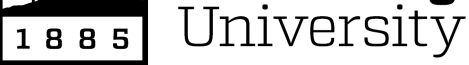

Michigan Technological University

Digital Commons @ Michigan Tech

\title{
JOINT SIMULATION OF CONTINUOUS AND CATEGORICAL VARIABLES FOR MINERAL RESOURCE MODELING AND RECOVERABLE RESERVES CALCULATION
}

Sentle Augustinus Hlajoane

Michigan Technological University, shlajoan@mtu.edu

Copyright 2020 Sentle Augustinus Hlajoane

Recommended Citation

Hlajoane, Sentle Augustinus, "JOINT SIMULATION OF CONTINUOUS AND CATEGORICAL VARIABLES FOR MINERAL RESOURCE MODELING AND RECOVERABLE RESERVES CALCULATION", Open Access Master's Thesis, Michigan Technological University, 2020.

https://doi.org/10.37099/mtu.dc.etdr/982

Follow this and additional works at: https://digitalcommons.mtu.edu/etdr

Part of the Geology Commons, Mining Engineering Commons, and the Multivariate Analysis Commons 
JOINT SIMULATION OF CONTINUOUS AND CATEGORICAL VARIABLES

FOR MINERAL RESOURCE MODELING AND RECOVERABLE RESERVES

CALCULATION

By

Sentle A. Hlajoane

A THESIS

Submitted in partial fulfillment of the requirements for the degree of

MASTER OF SCIENCE

In Geology

MICHIGAN TECHNOLOGICAL UNIVERSITY

2020

(C) 2020 Sentle A. Hlajoane 
This thesis has been approved in partial fulfillment of the requirements for the Degree of MASTER OF SCIENCE in Geology.

Department of Geological and Mining Engineering and Sciences

Thesis Advisor: Dr. Snehamoy Chatterjee

Committee Member: Dr. Nathan Manser

Committee Member: $\quad$ Dr. Greg Waite

Department Chair: $\quad$ Dr. John Gierke 


\section{Table of Contents}

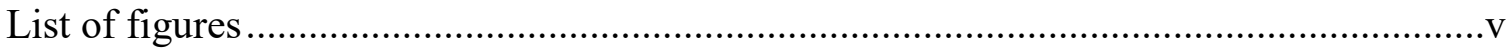

List of tables....................................................................................................... vii

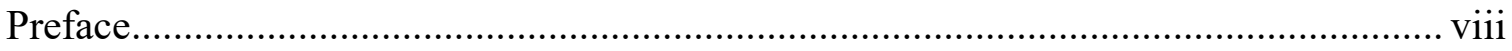

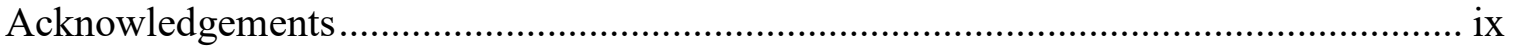

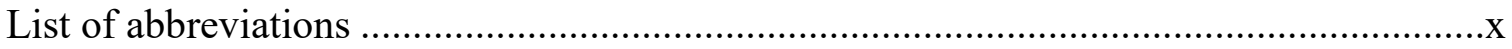

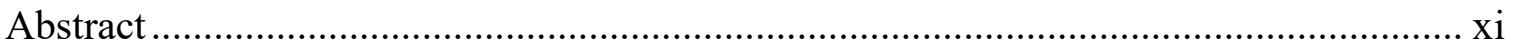

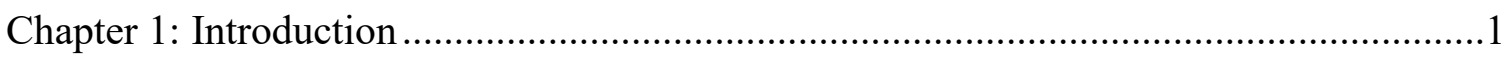

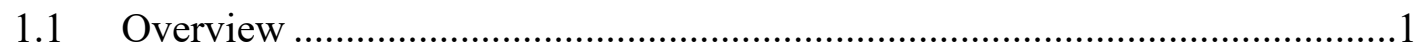

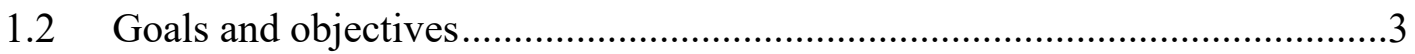

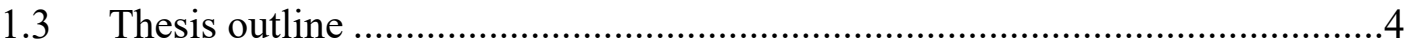

2 Joint simulation of continuous and categorical variables for mineral resource modeling and recoverable reserves calculation .........................................................5

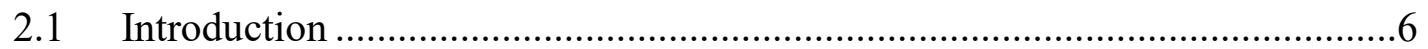

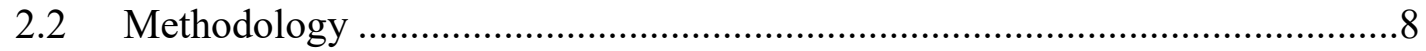

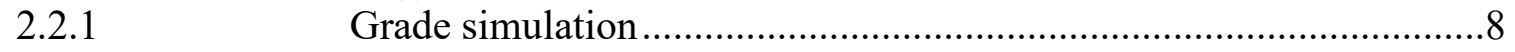

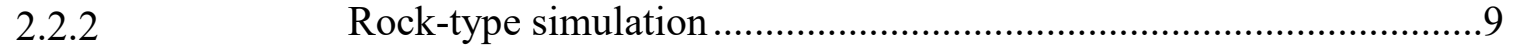

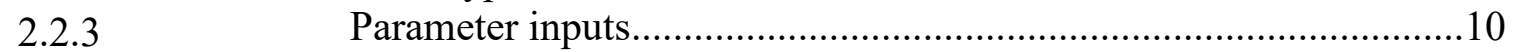

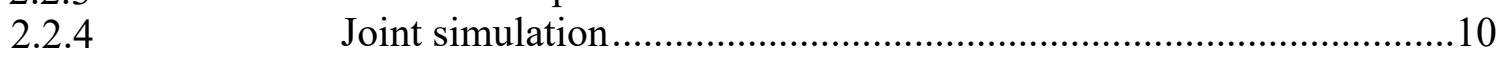

2.2.5 Resource classification............................................................ 11

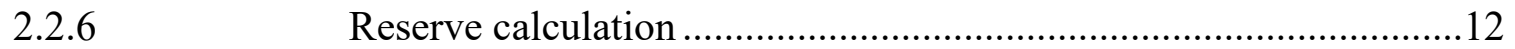

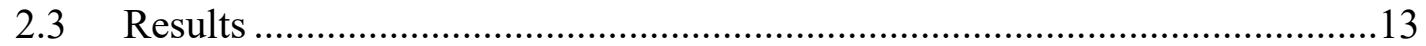

2.3.1 Location and geology of case study ............................................13

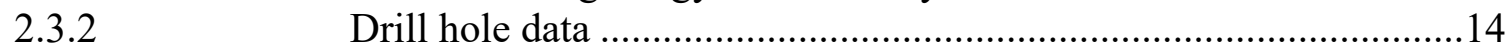

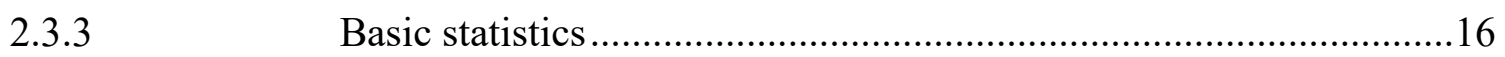

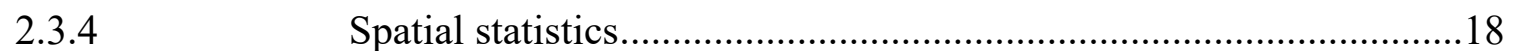

2.3.4.1 Grade modeling parameters ......................................18

2.3.4.2 Pluri-Gaussian parameters ..........................................19

2.3.5 Variogram analysis and spatial dependence modeling ....................23

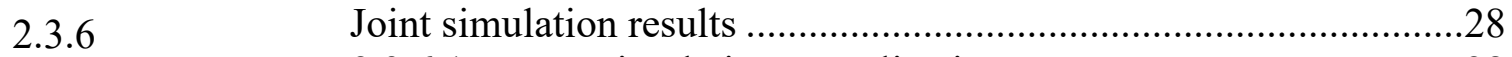

2.3.6.1 Co-simulation \& realizations .....................................28

2.3.6.2 Validation of the Joint Simulation Models ......................31

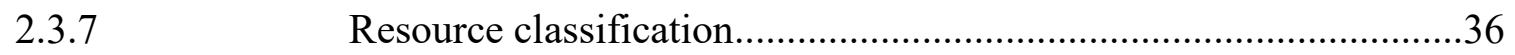

2.3.8 Reserve calculations........................................................... 41 
3 Conclusion and recommendation for future work

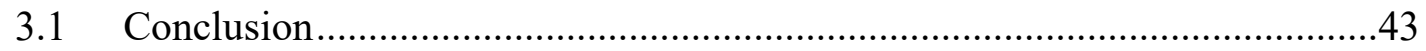

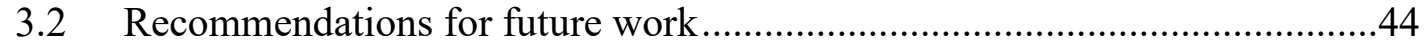

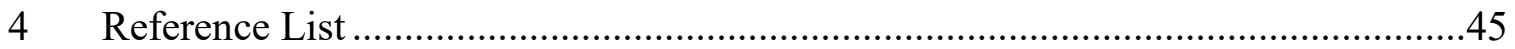




\section{List of figures}

Figure 11 Schematic summary of the Joint Simulation methodology............................11

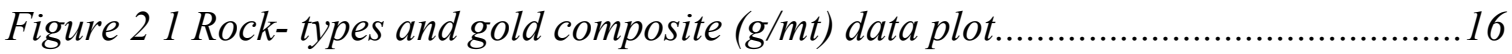

Figure 31 Histogram showing composite gold grade $(g / m t)$ in rock-types ......................17

Figure 41 Variogram model in three main directions of anisotropy..............................19

Figure 51 Truncation rule with thresholds along $\left(Y_{1}\right.$ and $\left.Y_{2}\right)$ fields ...........................21

Figure 61 Indicator variograms in three anisotropy directions (circles are experimental variograms \& solids are models).....................................................................25

Figure 71 Cross variograms between indicator and grade in three anisotropy directions (circles are experimental variograms \& solids are models).

Figure 81 Random grade realizations generated from the joint simulation

Figure 91 Random rock-type realizations generated from the joint simulation.

Figure 101 Histograms of simulated gold grades and composite grade from drill-hole data 
Figure 111 Variograms of simulated gold grades in X-direction, Y-direction and Zdirection compared with composite gold grades....

Figure 121 Drill holes conditioned to rock-types (before topographic removal) and box plot of all 25 realizations of rock-type proportions ...................................................35

Figure 131 E-type and Conditional Variance and Relative Conditional Variance Maps of

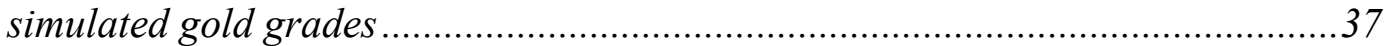

Figure 141 Grade tonnage curve showing mean, upper limit and lower limit uncertainty for tonnage and average grade of all the simulation........................................40 


\section{List of tables}

Table 11 Summary statistics of clustered Total Composite Gold grade (g/mt)

Table 21 Summary statistics of Declustered gold grade in individual rock-types and Total Composite Gold grade ( $\mathrm{g} / \mathrm{mt})$.....

Table 31 Parameters from trial and error coregionalization model

Table 41 Resource classification (Mmt=Million metric tonnes. Koz $=$ thousands of ounces)

Table 51 Summary of tonnage, grade and metal content uncertainty using joint simulation

Table 61 Economic parameter inputs for calculation of mineable blocks 41

Table 71 Grades and tonnages calculated from the reserves. 


\section{Preface}

The author of this thesis is the primary author in the paper included in chapter 2 in the

thesis. Dr. Snehamoy Chatterjee is the author's supervisor for the Master of Science degree and Amol Paithanker as the second co-author in chapter 2 of the thesis, which is submitted for journal publication. 


\section{Acknowledgements}

I would like to thank specifically my wife and family for the support they gave me while embarking on this journey. 


\section{List of abbreviations}

\begin{tabular}{|c|c|}
\hline CAM & : Cambrian rocks Unit \\
\hline UPS & : Upper Sediments \\
\hline MVC & : Main Volcanics \\
\hline LSS & : Lower Sediments \\
\hline$\%$ & : Percentage \\
\hline Prop. & : Proportions \\
\hline STDV & : Standard deviation \\
\hline $\mathrm{CV}$ & : Coefficient of variation \\
\hline g & : Grams \\
\hline $\mathrm{m}^{3}$ & : Cubic meter \\
\hline $\mathrm{mt}$ & : Metric tonnes \\
\hline $\mathrm{Mmt}$ & : Million metric tonnes \\
\hline oz. & : Ounces \\
\hline Koz & : Thousand ounces \\
\hline$\$$ & :US dollar \\
\hline
\end{tabular}




\section{Abstract}

Spatial variability and uncertainty of continuous variables (grade) and categorical variables (rock-types) in mineral evaluation significantly impact the economics of mining projects. The conventional approach of simulating grades using deterministic rocktypes is problematic since spatial variability, and uncertainty of grades at rock-type contacts are not well captured in deposits where the grade changes gradually between rock-types. Therefore, jointly simulating these variables can improve confidence (reduce uncertainty) in a resource model. Also, resource classification and recoverable reserve calculation can significantly improve the understanding of the deposit and its economic viability. This research utilized the Plural-Gaussian geostatistical simulation to jointly simulate rock-types and grade. A joint coregionalized model of random fields via fitting theoretical variograms is achieved. Equiprobable realizations of rock-types and grades are generated through a co-simulation of these variables. Resource classification of simulations and ultimate pit limit calculations are produced and validated using a real gold deposit in Alaska. 


\section{Chapter 1: Introduction}

\subsection{Overview}

Mineral resource modeling is an intrinsic task that involves extracting information from samples (drill-hole data) to estimates how much minerals are locked in a particular deposit, and also if they are economical enough to mine. Because of financial constraints during exploration drilling programs, a limited number of samples is normally used, making it more challenging to answer technical and economic questions. Besides limited information, one of the challenging factors is the geological complexity of a deposit in which uncertainty springs from. When keeping all factors constant, the homogenous deposit which is continuous along geological strike such as some bauxite deposits, are easier to model than heterogeneous deposits with multiple mineralized zones such as porphyry copper deposits and most gold deposits. In such heterogeneous deposits, mineralization is commonly associated with a specific rock-type(s), and therefore, the boundaries (contacts) between rock-types within a deposit become an important factor to cater for in a resource model. When grade changes gradually along rock-type boundaries, they are referred to as soft boundaries and hard boundaries when the transition is sharp or sudden. A resource model becomes more useful when it addresses logical estimation and provides a way of measuring risk in that estimation.

In mining, understanding the interplay between continuous (grade) and categorical variables (rock-types) is vital because they are the critical inputs in the quantification of mineral resources, the definition of mineral reserves and production scheduling which determine the success of mining projects (Montoya et al., 2012). The Gaussian Random Field, which involves a Gaussian Probability density function of the random variables and determined by mean and a covariance function (Journel, 2003; Lantuéjoul, 2012), is employed to enable modeling of these two different variables. The spatial variability of these variables is, therefore, important as grade models are used to evaluate resource and reserve estimates and depict how grade varies across different geological domains or rocktypes (Emery, 2007). Categorical variables are commonly used to map out stationary 
domains, especially in the mining industry (Pyrcz and Deutsch, 2014; Rossi and Deutsch, 2014), which act as a host for simulation of continuous variables such as grade. Therefore, modeling rock types is vital because these models generate probabilistic descriptions of geological domains and also contributes to enhancing geological control for the quantitative petro-physical variable such as grade when these variable are homogenous within each geological domain, but the layout of the domain boundaries is uncertain (Deutsch and Silva, 2016).

Various methods have been used to model grades and rock types. A common traditional method of grade modeling uses a Multi-Gaussian approach where a step-by-step or Cascade method is used as described by (Journel and Huijbregts, 1978), at which different rock types are selected using a deterministic model based on geological knowledge and any other supporting data (Mackenzie and Wilson, 2001). Because these deterministic cascade models do not cater to the uncertainty of grades and tonnages, this can lead to under-estimation of tonnage and over-estimation of grade which is undesirable in mining project (Goodfellow et al., 2012). In less complex deposits, conceptual and deterministic models still suffer from the same impediment of uncertainty as only one set of deductions is made about the deposit (Jones et al., 2013). The cascade method works under the assumption that the spatial correlation between grades and changing rock types is poor and therefore ignorable (Kim et al., 2005), but in cases where there is a gradual change of grade in changing rock types. this method will not provide the best results as spatial correlation might be too significant to ignore (Emery and Silva, 2009). Moreover, mineral resource estimation using deterministic models (kriging and its variants) produces the smoothing effect of kriging rendered maps biased for any selection; therefore, it fails to account for uncertainty in the deposit being estimated (Rossi and Deutsch, 2013). Furthermore, the estimation variance, whose minimization defines kriging and, more generally, all projection-type estimators, is an incomplete measure of estimation accuracy since it is data values-independent (Journel, 2003).

To address the challenge of uncertainty in reporting tonnages while evaluating ore bodies, different stochastic simulation algorithms have been adopted for treating the glitches that 
come with rock-type models (Osterholt and Dimitrakopoulos, 2007). Methods such as Sequential Indicator Simulation (SIS), which uses Indicator Kriging (IK) instead of conditional simulation to estimate the probability of categorical variables (Goovaerts, 1997; Sojdehee et al., 2015) often lack accuracy (Emery, 2004). Another drawback of using SIS is that it fails to reproduce the ordering of categories more so when then deposit under evaluation is sparsely sampled (Deutsch and Silva, 2016). Multipoint Geostatistics is also an advanced method used for quantifying uncertainty through Training Image, instead of the conventional variogram based two point methods (Guardiano and Srivastava, 1993). Goodfellow et al., (2012) and Paithanker and Chatterjee (2017) applied Single Normal Equations Simulation (SNESIM), a multiple-point geostatistical method, to determine the uncertainty of tonnages in polymetallic deposit at Coleman MacCreedy deposit and a copper deposit in Africa, respectively. The pixel-based of multi-point geostatistics method, are found to replicate accurate matches with drill hole data, but in complex geological settings provide somehow limited reproduction of structures (Tahmasebi, 2018).

For tackling the smoothing effect and uncertainty issues in estimated resources caused by Kriging, Sequential Gaussian Simulation provides a solution through multiple realizations capturing uncertainty (Deutsch and Journel, 1998; Pyrcz and Deutsch, 2014). The success of this method has been in estimating different heterogeneous deposits in order to capture grade boundary problems such as soft or hard boundaries through the use of variogram models to quantify uncertainty in both copper grade and geological boundaries (Maleki and Emery, 2015). The limitations of Sequential (or cascade) rock-type and grade modeling is that multiple realizations for each variable are produced separately which increases the compounded error that comes with handling them, while performing a joint simulation reduces those errors hence improve the resource model accuracy (Dominy et al., 2004).

\subsection{Goals and objectives}

The goal of the thesis is to jointly simulate (model) continuous variable (grade) with a categorical variable (rock-type) to develop a resource model where grades and tonnages 
are estimated, incorporating uncertainties from both the sources. The importance of simulating grades and rock-types together is to reduce compounded error that comes with simulating them separately; for mining purposes, such errors result in poor mine planning and production losses. Capturing uncertainty is also critical because it provides a measure of risk associated with the estimation and therefore provides a financial tool to guide the economics of a mining project. The first objective is capture, if present. any spatial correlation between grades across rock types (Lui, 2006). The second objective is to assign a measure of uncertainty which will be covered by multiple realizations created after simulation (Emery and Silva, 2009). Then the last objective is to develop a mineral resource classification and reserve calculation based on the realizations generated from the joint simulation. To attain the above objectives, previous work done on grade estimation and rock-type modeling using various methods are revisited. Then a proposed methodology of Pluri-Gaussian simulation and Multi-Gaussian simulation are used to jointly simulate rock-types and grade producing multiple equiprobable images of each variable. Measure and indicated resources together with proven and probable reserves are estimated using relative conditional variance and maximum flow algorithm respectively. A heterogeneous gold deposit is used as a case study for the results and validation of our objectives.

\subsection{Thesis outline}

The thesis is organized in the following manner;

Chapter 1: An overview of the joint simulation of grades and rock-types for resource modeling is presented in this chapter, and the setbacks of conventional methods are also presented here.

Chapter 2: Joint simulation of grades and rock-types for resource modeling is presented, and results are validated through the summary and spatial statistics from a case study. Resource classification and reserve calculation are also included for analysis. The case study is used as validation and for the method.

Chapter 3: Overall conclusions and recommendations for future work are presented. 


\title{
2 Joint simulation of continuous and categorical variables for mineral resource modeling and recoverable reserves calculation
}

(The material contained in this chapter will be submitted for possible publication in

'Natural Resources Research' journal)

\begin{abstract}
Spatial variability and uncertainty of continuous variables (grade) and categorical variables (rock-types) in mineral evaluation significantly impact the economics of mining projects. The conventional approach of simulating grades using deterministic rock-types is problematic since spatial variability, and uncertainty of grades at rock-type contacts are not well captured in deposits where the grade changes gradually between rock-types. Therefore, jointly simulating these variables can improve confidence in a resource model while reducing the uncertainty at contact boundaries. The resource classification and recoverable reserve calculation using multiple equiprobable simulation maps can also significantly improve the understanding of the deposit and its economic feasibility to do mining. This research proposed the Pluri-Gaussian geostatistical simulation algorithm to jointly simulate rock-types and grade, where the variograms and cross variograms parameters of the Gaussian random fields are iteratively optimized. A joint model of these random fields via theoretical variograms is achieved through a coregionalized model with various parameters (coefficients) depending on the model inputs. Equiprobable realizations of rock-types and grades are generated through a co-simulation of these variables. Resource classification of joint simulations and ultimate pit limit calculations are produced and validated using a real gold deposit in Alaska. Average grades from measured and indicated resources are 0.6142 and $0.5197 \mathrm{~g} / \mathrm{mt}$ respectively. Ultimate pit results show recoverable reserves with an average grade of $0.6303 \mathrm{~g} / \mathrm{mt}$ proven and $0.5442 \mathrm{~g} / \mathrm{mt}$ probable.
\end{abstract}




\subsection{Introduction}

In mining, understanding the interplay between continuous (grade) and categorical variables (rock-types) is vital because they are the critical inputs in the quantification of mineral resources, the definition of mineral reserves, and production scheduling which determine the success of mining projects (Montoya et al., 2012). The Gaussian Random Field, which involves a Gaussian Probability density function of the random variables and determined by mean and a covariance function (Journel, 2003; Lantuéjoul, 2012), is employed to enable modeling of these two different variables. The spatial variability of these variables is, therefore, important as grade models are used to evaluate resource and reserve estimates and depict how grade varies across different geological domains or rocktypes (Emery, 2007). Categorical variables are commonly used to map out stationary domains, especially in the mining industry (Pyrcz and Deutsch, 2014; Rossi and Deutsch, 2014), which act as a host for simulation of continuous variables such as grade. Therefore, modeling rock types is vital because these models generate probabilistic descriptions of geological domains and also contributes to enhancing geological control for the quantitative petro-physical variable such as grade when these variable are homogenous within each geological domain, but the layout of the domain boundaries is uncertain (Deutsch and Silva, 2016).

Various methods have been used to model grades and rock types. A common traditional method of grade modeling uses a Multi-Gaussian approach where a step-by-step or Cascade method is used as described by (Journel and Huijbregts, 1978), at which different rock types are selected using a deterministic model based on geological knowledge and any other supporting data such as similar deposits already mined (Mackenzie and Wilson, 2001). Because these deterministic cascade models do not cater to the uncertainty of grades and tonnages, this can lead to under-estimation and over-estimation of grade and tonnage which is undesirable in mining project (Goodfellow et al., 2012). In less complex deposits, conceptual and deterministic models still suffer from the same impediment of uncertainty as only one set of deductions is made about the deposit (Jones et al., 2013). The cascade method works under the assumption that the spatial correlation between grades and 
changing rock types is poor and therefore ignorable (Kim et al., 2005), but in cases where there is a gradual change of grade in changing rock types. This method will not provide the best results as spatial correlation might be too significant to ignore (Emery and Silva, 2009). Moreover, mineral resource estimation using deterministic models (kriging and its variants) produces the smoothing effect of kriging rendered maps biased for any selection; therefore, it fails to account for uncertainty in the deposit being estimated (Rossi and Deutsch, 2013). Furthermore, the estimation variance, whose minimization defines kriging and, more generally, all projection-type estimators, is an incomplete measure of estimation accuracy since it is data values-independent (Journel, 2003).

To address the challenge of uncertainty in reporting tonnages while evaluating ore bodies, different stochastic simulation algorithms have been adopted for treating the glitches that come with rock-type models (Osterholt and Dimitrakopoulos, 2007). Methods such as Sequential Indicator Simulation (SIS), which uses Indicator Kriging (IK) instead of conditional simulation to estimate the probability of categorical variables (Goovaerts. 1997; Sojdehee et al., 2015) often lack accuracy (Emery, 2004). Another drawback of using SIS is that it fails to reproduce the ordering of categories more so when then deposit under evaluation is sparsely sampled (Deutsch and Silva, 2016). Multipoint Geostatistics is also an advanced method used for quantifying uncertainty through Training Image, instead of the conventional variogram based two point methods (Guardiano and Srivastava, 1993). Goodfellow et al., (2012) and Paithanker and Chatterjee (2017) applied Single Normal Equations Simulation (SNESIM), a multiple-point geostatistical method, to determine the uncertainty of tonnages in polymetallic deposit at Coleman MacCreedy deposit and a copper deposit in Africa, respectively. The pixel-based variant methods of Multi-Point Geostatistics, are found to replicate accurate matches with drill hole data, but in complex geological settings provide somehow limited reproduction of structures (Tahmasebi, 2018).

For tackling the smoothing effect and uncertainty issues in estimated resources caused by Kriging, Sequential Gaussian Simulation provides a solution through multiple realizations capturing uncertainty (Deutsch and Journel, 1998; Pyrcz and Deutsch, 2014). The success 
of this method has been in estimating different heterogeneous deposits in order to capture grade boundary problems such as soft or hard boundaries through the use of variogram models to quantify uncertainty in both copper grade and geological boundaries (Maleki and Emery, 2015). The limitations of Sequential Gaussian Simulation for (or cascade) rock-type and grade modeling is that multiple realizations for each variable are produced separately which increases the compounded error that comes with handling them, while performing a joint simulation reduces those errors hence improve the resource model accuracy (Dominy et al., 2004).

\subsection{Methodology}

\subsubsection{Grade simulation}

Our ultimate goal is to produce a joint simulation of grades and rock-types for grade modeling, so we used the turning bands algorithm for non-conditional co-simulation of Gaussian Random Fields followed by conditioning co-kriging (Emery and Lantuéjoul, 2006). This algorithm is a suitable choice for our purpose because it allows us to crosscorrelate Gaussian Random Fields conditionally to the data. As a way of making sure the data provides the best results, the data is declustered if it shows clustering issues and normalized if its distribution is skewed. Different kinds of algorithms for declustering can be used depending on the data and normal score transformation for normalizing the grades (Gaussian data) as shown in Eq. (1).

Moreover, to determine spatial continuity parameters such as the orientation of maximum and minimum continuity (directional anisotropies), variogram map analysis is done through a rose diagram. Experimental variograms in the horizontal and vertical directions, depending on different lag values, are constructed and fitted with a covariance function which best describes spatial variability of grade in the deposit. This variogram model of the Gaussian transformed grade data becomes the first Gaussian Random Field (GRF) with the appropriate number of nested structures and ranges along with the anisotropic directions, it is denoted by $Y_{0}$. 
The model parameters of this GRF become inputs to determine other proposed Gaussian Random Fields for the indicator/s. A non-decreasing function using the turning bands, sequential or spectral simulation provided in the code developed by Emery (2009), is used for simulating these GRFs (Chiles and Delfiner, 1999). The simulated results are then backtransformed from normal score grades into original grades, and various grade realizations are drawn from the simulation.

$$
\forall x \in R^{3} \cdot Z_{0}(x)=\varnothing\left(Y_{0}(x)\right)
$$

Where. $\forall x \in . \forall i \in\{1 \ldots \ldots n\} . \varnothing$ a normal score transformation function and $Z_{0}$ is a monotonic function of a Gaussian Random Field $Y_{0}$.

\subsubsection{Rock-type simulation}

Categorical data modeling is done by transforming the rock-types into indicator data. The rock-types are transformed into indicators $\left(I_{K}\right)$ using the following relationship;

$$
I_{K}(x)= \begin{cases}1, & \text { if } x \text { belongs to the Kth rock type } \\ 0, & \text { otherwise }\end{cases}
$$

According to the contacts in the drill hole data and the proportions of individual rocktypes, a rock-type rule is chosen to capture the spatial boundaries between the rock-types. Following the rock-type rule, the truncation rule determines how many Gaussian random fields are needed to fully describe the rock-type model. If the number of Gaussian random fields for the indicators is more than two, the model becomes a Pluri-Gaussian model, while the former condition of one Gaussian random field, is generally referred to as the Truncation Gaussian model (Lantuéjoul, 2002; Dowd et al., 2003; Armstrong et al., 2011). The thresholds which discretize the Gaussian random fields are determined through the 
proportions of individual rock types through the Standard Gaussian cumulative distribution function (Betzhold and Roth, 2000).

The spatial relationship of the selected categorical GRF is modeled to fit the indicator variograms (Emery and Maleki, 2014). Gibbs sampling technique is then used to simulate a set of Gaussian values generated at each data location conditionally to the categorical information at this location and the previously simulated Gaussian values (Emery, 2007).

\subsubsection{Parameter inputs}

For fitting the experimental indicator semi-variograms, cross semi-variograms between Gaussian (normal score transformed grade) and indicators that complete our coregionalization model, an interactive method together with its associated code developed by Emery (2009), is used. The primary input parameter is the transformed grade covariance function, which is used as the underlying first GRF, with its sills being constants in the covariance matrix. The truncation rule in the Pluri-Gaussian model determines how many GRF are generated from the indicator variable, and they are brought as inputs into the model. Diagonal entries in the coregionalization model represent the direct variogram of all determined GRFs while the non-diagonal entries become coefficients depending on GRF's spatial relationships. Eventually, a trial and error modification of the coefficients provide the best fit for all the semi-variograms completing the GRFs of the indicator data, which will be used with the transformed grade GRF for a joint simulation.

\subsubsection{Joint simulation}

Now that all the underlying GRFs for both the transformed grade and indicators and all other input parameters are determined, a joint simulation is the next step (Emery and Lantuèjoul, 2006; Emery, 2008). To achieve this, the primary assumption is that our coregionalization matrix is a linear model and, therefore, covariance and cross covariances are assumed to be within similar nested basic structures (Wachernagel, 2003). For representation, the first Gaussian Random Field is denoted by $\left(\mathrm{Y}_{0}\right)$ for the transformation grade and other Gaussian Random Fields for the indicator denoted as $\left(Y_{1}, Y_{2} \ldots Y_{n}\right)$. So, at 
each location within the rock-type data, a vector Gaussian Random Field (Y) is simulated conditionally to the transformed grade data and rock types through the Gibbs sampler. The turning bands co-simulates the Gaussian Random Fields $\left(\mathrm{Y}_{0}, \mathrm{Y}_{1}, \mathrm{Y}_{2} \ldots \mathrm{Y}_{\mathrm{n}}\right)$ through decomposing these GRF into non-correlated factors via the coregionalization model (Emery, 2008; Maleki and Emery, 2014). Once the joint simulation is complete, a back transformation function is employed for transformation grade back into original grades and a truncation rule for transforming indicator back to rock-types (Emery and Silva, 2009). A summary of the method is shown in Figure 1.

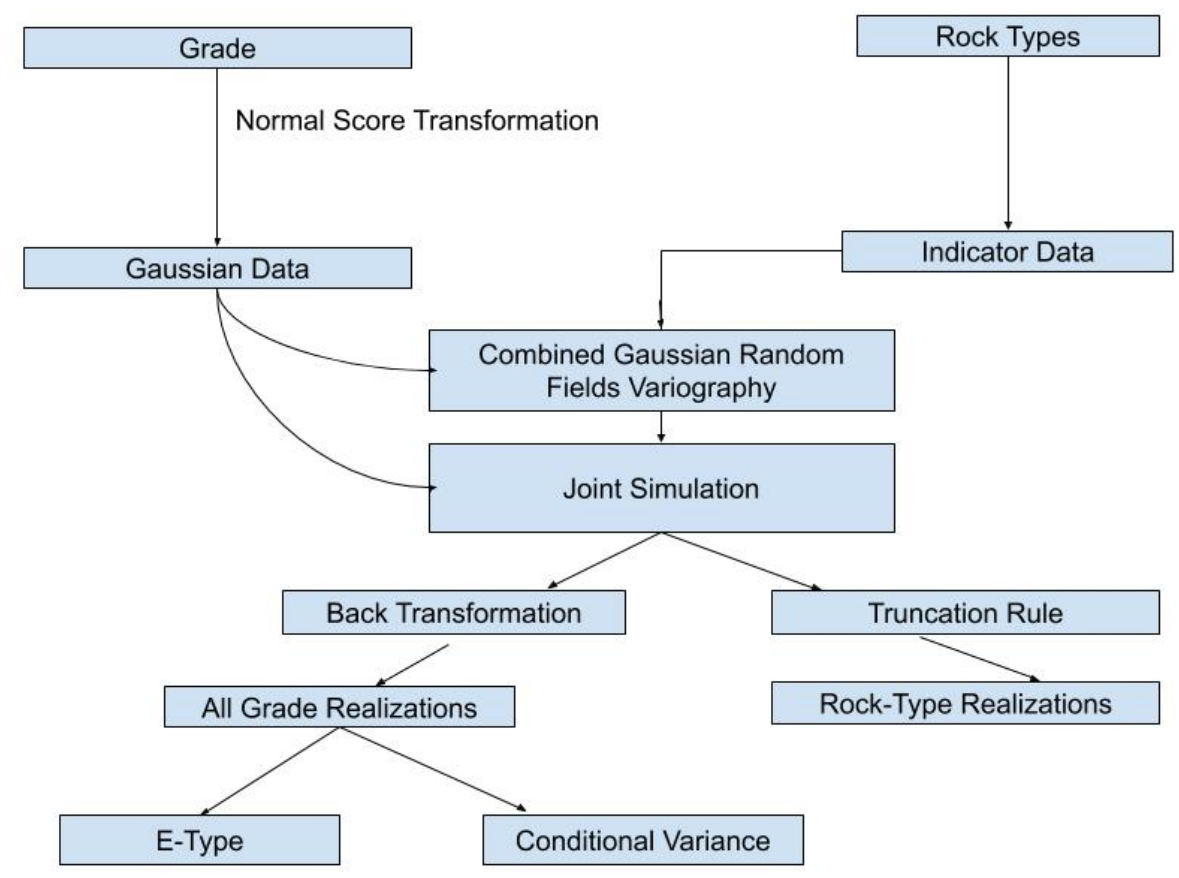

Figure 11 Schematic summary of the Joint Simulation methodology

\subsubsection{Resource classification}

Resource classification is an important step in estimating the quantity of mineral resources within a deposit into blocks whereby individual blocks are classified with an increasing level of geological confidence (Ortiz et al., 2006). The quality of resource classification is 
paramount for economic and risk evaluations, and therefore it does not only rely on the amount of data (geological confidence) available, but also on the quality of data being used (Silva and Boisvert, 2014). There are several types of techniques used for classifying mineral resources, which are chosen depending on the orebody being evaluated. Some authors have proposed and used classification techniques such as search neighborhoods, drill-hole spacing, and kriging variance (Sinclair and Blackwell, 2002). In this thesis, we classified our resources based on conditional simulation. The advantage of using this technique is that it addresses the issue of heteroscedasticity where true variance and covariance are underestimated and therefore impacts accuracy for resource classification (Dohm, 2004). Depending on the objective, classification techniques using conditional simulation can be carried according to volumes (tonnages), precision, and confidence interval. Authors such as Deutsch et al., (2006), Dominy et al., (2002), Snowden (2001), and Wawruch and Betzhold (2005) have put forward and used conditional simulation in various deposits.

The realizations generated from the joint simulation were post-processed and an average of the realizations (E-type), was determined together with conditional variance generated from the realizations conditioned to the data. The inputs for calculating resource classes were the mean data (E-type), conditional variance, and thresholds for classifying measured, indicated and inferred resources. We also used an option of relative conditional variance because it measures relative error and, therefore, does not favor or penalize either high or low-grade areas (Ortiz et al., 2006).

\subsubsection{Reserve calculation}

The Canadian Institute of Mining, Metallurgy, and Petroleum (CIM) defines mineral reserves as the economically mineable part of a measured or indicated mineral resource demonstrated by at least a preliminary feasibility study. Open pit mining operations depend on the proper design of the ultimate pit for optimal production planning (Chatterjee et al., 2016). Our objective is to determine the tonnages of mineable reserves for which the ultimate pit determination will take care of (Marcotte and Caron, 2013). We used the 
maximum flow minimum cut algorithm, which solves the problem of finding a maximal closure within a mine graph where a minimum cut determines an optimal pit contour (Hochbaum, 2001). This algorithm solves the problem of finding the best combination of desirable and non-desirable blocks that result in the maximization of profit. The following mathematical formulation was used for the mineable reserve calculation:

Objective Function:

$$
\begin{gathered}
\text { Maximize } \sum_{\gamma \in \Gamma} \sum_{b \in B} v_{\gamma b} x_{b} \\
x_{b}-x_{b^{\prime}} \leq 0, \quad b^{\prime} \in \xi_{b}, \quad b \in B \\
x_{b} \in\{0,1\}, b \in B
\end{gathered}
$$

Where, $v_{\gamma b}$ is the economic value of mining block $b$ from simulation $\gamma \cdot x_{b}$ is the binary decision variable, which takes value 1 if mining block $b$ is inside the pit, 0 otherwise, $b^{\prime}$ is the block that needs to mine before mining block $b$ to satisfy slope constraints, $\Gamma$ is number simulated orebody models, and $B$ is the number of mining blocks present in the orebody model. The objective function of Eq. (3) tries to maximize the total cash flow (profits) from the deposit; whereas, Eq. (4) is precedence constraints, which ensures respecting the slope of the ultimate pit. From resource classification. only the measured and indicated resources are satisfying economic and slope constraints within the ultimate pit are classified as proven and probable reserves respectively.

\subsection{Results}

\subsubsection{Location and geology of case study}

The study area is located in Alaska within the Tintina Gold belt. This region consists of Intrusion Related Gold Systems (IRGS), which are characterized by intermediate to felsic 
composition intrusions near the ilmenite-magnetite series boundary with carbonic hydrothermal fluids and, therefore gold mineralization is related to this intrusive system (Lang et al., 2000). Gold occurring in this system is associated with Bi, W, As, Mo, Te, and low base metal concentrations. Gold mineralization is also associated with disseminated arsenopyrite and pyrite in volcanics, sedimentary and intrusive rocks, and in quartz veins cutting the more competent lithologies, primarily volcanic rocks, sandstones, and to a lesser degree, ultramafic rocks. These gold-bearing quartz veins are associated with dikes, sill, and stocks of monzonite, diorite, and syenite in composition (Ebert et al., 2000). Mineralization of the volcanic section is continuous for at least $600 \mathrm{~m} \mathrm{E-W}$ and $375 \mathrm{~m}$ N-S. Detailed isotopic and geochemical studies establish possible sources for the hydrothermal fluids and associated molten rock; these results help refines the overall genetic exploration model for the epizonal gold deposits in the area (Hart et al., 2002).

The sequence of the rocks in this particular study area consists of the older Cambrian ophiolite mafic and ultramafic rocks that are over-thrust younger sediments and volcanic rocks. For this study, the rock-types are identified as Cambrian rocks (CAM), Upper Sediments (UPS), Main Volcanics (MVC) and Lower Sediments (LSS) The (CAM) overlie (UPS), which form a layer of gold hosting sedimentary formations. The (MVC) can be in contact with both the CAM and UPS depending on which location is sampled. This is mainly driven by faults, which in turn enable contacts between the UPS and the Lower Sediments (LSS), which ideally are beneath the volcanic unit where there faulting is no faulting. Structurally, from top to bottom, these rock units are sub-horizontal to $45^{\circ}$ dipping to the South. Drill hole sampling is mainly located to the South of the Lillian Fault with little attention given to the sedimentary and volcanic units into the North of it due to low mineralization. Mineralization is mainly hosted in the UPS, LSS, and MVC.

\subsubsection{Drill hole data}

Drill holes were collected through an exploration program with more than $90 \%$ of the holes drilled in the northerly direction. Diamond drilling core samples are collected at a spacing of $75 \mathrm{~m}$ inclined at about $-50^{\circ}$ and reverse circulation holes ranging between 0 and $30 \mathrm{~m}$ 
spacing inclined at about $-60^{\circ}$. Because of the dip of the mineralization, these inclinations are intended to intercept these south-dipping ore bodies closer to $90^{\circ}$. From the drill hole data, the proportions of these four rock-types show thin layers such as in UPS and LSS. Therefore, for compositing, a down the hole within rock-type method of $2 \mathrm{~m}$ length is considered to capture enough data points for further analysis. The average rock density was $2.7 \mathrm{mt} / \mathrm{m}^{3}$ with an estimated block size of $15 \mathrm{~m} \times 15 \mathrm{~m} \times 10 \mathrm{~m}$. with 140, 120, and 50 blocks along the $\mathrm{X}, \mathrm{Y}$, and $\mathrm{Z}$ directions. respectively. Because of mineralization anomalies, drilling is mainly focused on the southern part of the deposit, and therefore, data clustering is evident from the drill holes, as shown in Figure 2 and is summarized in table 1. A cell declustering algorithm is used to address clustering in the data.

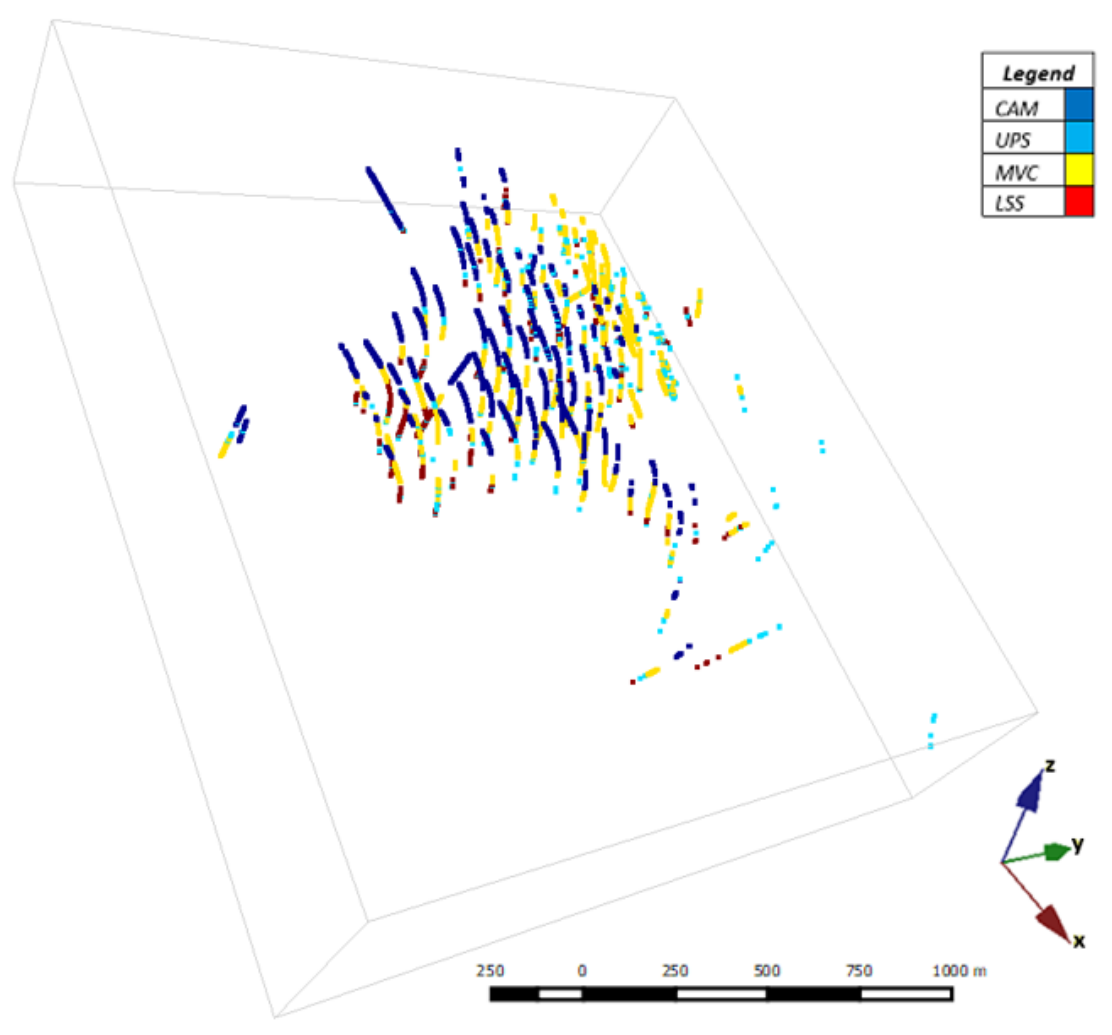




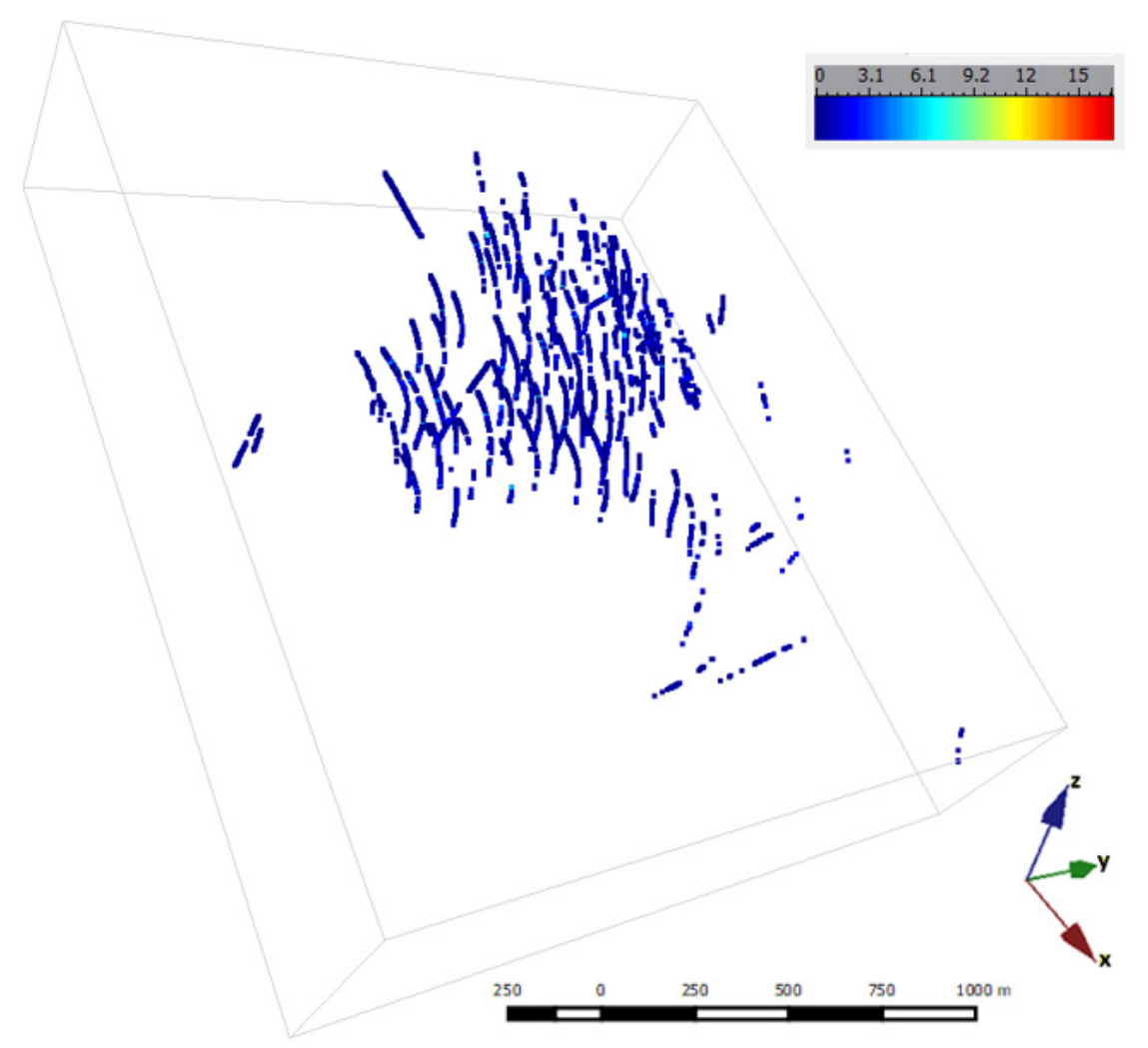

Figure 21 Rock-types and gold composite (g/mt) data plot

Table 11 Summary statistics of clustered total composite gold grade (g/mt)

\begin{tabular}{|l|c|}
\hline Data \# & 8730 \\
\hline Mean & 0.4598 \\
\hline Variance & 0.9416 \\
\hline STDV & 0.9704 \\
\hline Range & 24.8667 \\
\hline CV & 2.1106 \\
\hline Median & 0.1834 \\
\hline
\end{tabular}

\subsubsection{Basic statistics}

A total of 8716 data points are determined from the $2 \mathrm{~m}$ composite data covering all the drill holes represented in the study domain. Gold concentrations summary statistics in each rock-type are represented in table 2. The histograms in Figure 3 indicate positive skewness for the grades within each of the four rock types. Variability within the CAM unit is less compared to the other three rock types, even though it's extremely skewed. It is also evident 
that the low gold concentrations are mainly found in the CAM Unit, while the other three rock-types have varying concentrations of gold above the total grade average within the deposit. These statistics are in line with geological interpretations of mineralization in this study area where pockets of quartz gold-bearing veins cross-cut mainly the UPS, MVC, and LSS rock-types. For spatial analysis, because of the positive skewness of the grade within the deposit, a transformation using normal scores is used to normalize the data (Templeton, 2011).
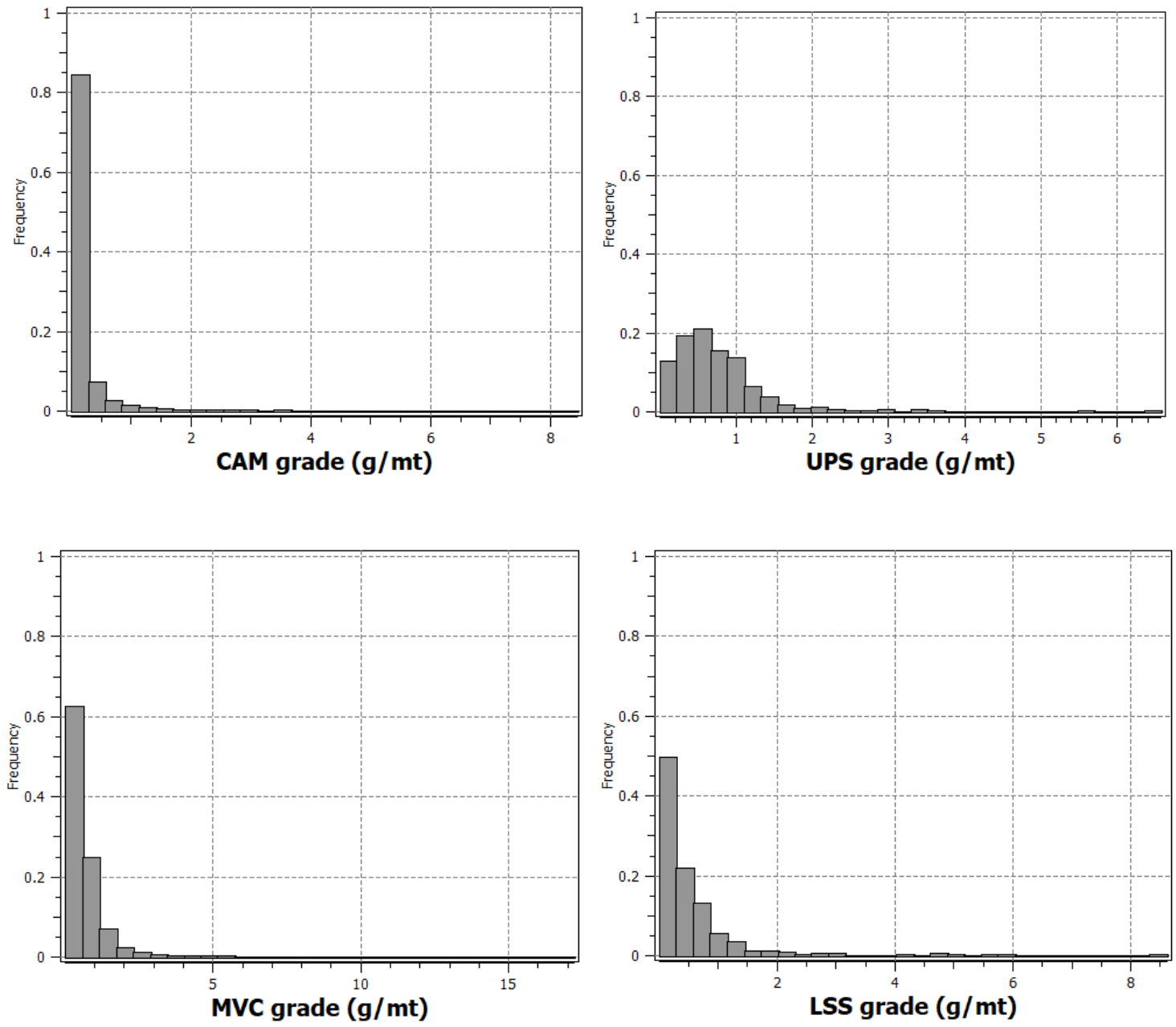

Figure 31 Histograms showing composite gold grade(g/mt) in rock-types 
Table 21 Summary statistics of declustered gold grade in individual rock-types and total composite gold grade ( $\mathrm{g} / \mathrm{mt})$

\begin{tabular}{|l|c|c|c|c|c|c|c|c|}
\hline $\begin{array}{l}\text { Rock } \\
\text { Type }\end{array}$ & $\begin{array}{c}\text { Data } \\
\#\end{array}$ & $\begin{array}{l}\text { Prop. } \\
(\%)\end{array}$ & Mean & Variance & STDV & Median & Range & CV \\
\hline CAM & 3891 & 45 & 0.1952 & 0.2917 & 0.5402 & 0.0318 & 8.4460 & 2.7674 \\
\hline UPS & 507 & 6 & 0.7554 & 0.4211 & 0.8372 & 0.6300 & 6.5650 & 1.1082 \\
\hline MVC & 3885 & 44 & 0.6279 & 0.7600 & 0.8712 & 0.4114 & 17.207 & 1.3874 \\
\hline LSS & 433 & 5 & 0.5398 & 0.7008 & 0.6489 & 0.3000 & 8.5988 & 1.2021 \\
\hline $\begin{array}{l}\text { Total } \\
\text { Grade }\end{array}$ & $\mathbf{8 7 1 6}$ & $\mathbf{1 0 0}$ & $\mathbf{0 . 4 3 7 7}$ & $\mathbf{0 . 5 7 6 9}$ & $\mathbf{0 . 7 5 9 5}$ & $\mathbf{0 . 1 8 2 0}$ & $\mathbf{1 7 . 2 0 9 5}$ & $\mathbf{1 . 7 3 5 2}$ \\
\hline
\end{tabular}

\subsubsection{Spatial statistics}

\subsubsection{Grade modeling parameters}

Normal score transformed grade data variograms analysis show major direction along NE $140^{\circ}$, semi-major along $\mathrm{NE} 50^{\circ}$ and minor direction along the vertical. Experimental variograms in the horizontal directions were calculated at a lag of $30 \mathrm{~m}$, which is almost half the spacing of the drill holes, while in the vertical direction a lag of $2 \mathrm{~m}$ was used because of some of the thin rock-types such as the UPS and LSS in this deposit. The fitted model has a nugget and two exponential nested structures portraying Geometric and Zonal anisotropies, as shown in Figure 4. The high nugget value is a common phenomenon in gold deposits, and the quartz vein mineralization cross-cutting the rock-types could be suspect of this variability in the vertical direction. Moreover, the variogram model agrees with the exploration observation of mineralization being continuous for at least $600 \mathrm{~m}$ in the horizontal directions.

$$
\begin{gathered}
\gamma_{00}=0.40 \text { nugget }+0.40 \exp (307,202,120) m \\
+0.20 \exp (750,750,165) m
\end{gathered}
$$




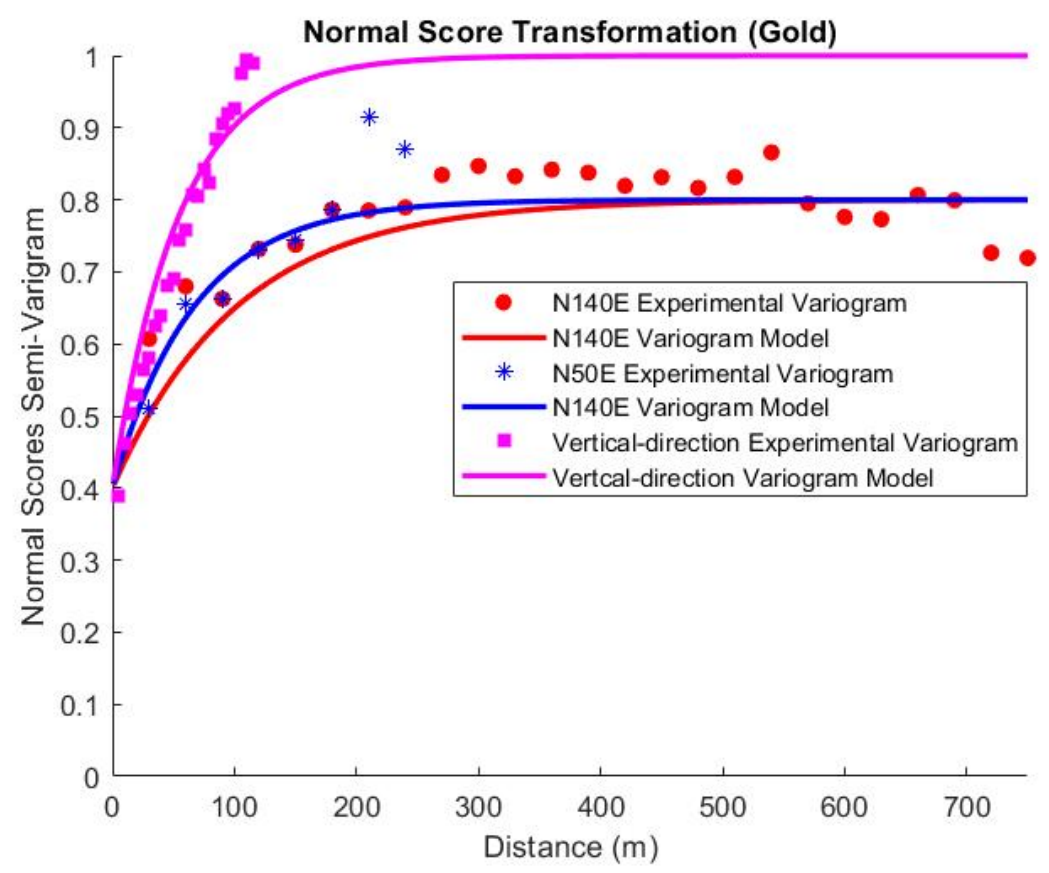

Figure 41 Variogram model in three main directions of anisotropy.

\subsubsection{Pluri-Gaussian parameters}

From the drill hole data, the CAM, UPS, and MVC can be in contact with each other depending on their spatial location in space. Another visible contact is between the MVC, UPS, and LSS rock-types. Furthermore, contact analysis indicates there is no contact between the CAM and LSS rock-types. These contact observations are used in the PluriGaussian model. For simulation, indicator variables are used to decide which point lies within which rock-type. In the domain space of the deposit, the indicator variable is assigned a value of 1 where a specific rock-type is present and assigned 0 , where it is not. Figure 5 shows how this relationship is captured so as to utilize the rock-type rule for all the rock-types. If $x$ represents the position in 3-D space, the indicator representation of four rock-types are described in the following way:

$$
\operatorname{Icam}(x)=\left\{\begin{array}{c}
1 \text { if } x \text { belongs to CAM } \\
0 \text { otherwise }
\end{array}\right.
$$




$$
\begin{aligned}
& \operatorname{Iups}(x)=\left\{\begin{array}{c}
1 \text { if } x \text { belongs to UPS } \\
0 \text { otherwise }
\end{array}\right. \\
& \operatorname{Imvc}(x)=\left\{\begin{array}{c}
1 \text { if } x \text { belongs to MVC } \\
0 \text { otherwise }
\end{array}\right. \\
& \operatorname{IlsS}(x)=\left\{\begin{array}{c}
1 \text { if } x \text { belongs to LSS } \\
0 \text { otherwise }
\end{array}\right.
\end{aligned}
$$

From global proportion statistics of individual rock-types shown in Table 2, the proportions statistics must be preserved in the realizations after simulation. Because of the spatial characteristics evident from the rock-type contacts and proportions, two dependent Gaussian Random Fields $\left(Y_{1}\right.$ and $\left.Y_{2}\right)$ were selected to best describe the rock-type interactions within the deposit as indicated in Figure 5.

These Gaussian Random Fields allow thresholds to be decided, which in turn, the thresholds truncate these fields according to the contacts while the proportions are determined from the standard probability statistics. Gaussian random field (Y1) was defined by truncating one threshold $\left(t_{2}\right)$ while Gaussian Random Field $(Y 2)$ was defined by truncating two thresholds $\left(t_{1}\right.$ and $\left.t_{1}{ }^{\prime}\right)$. 


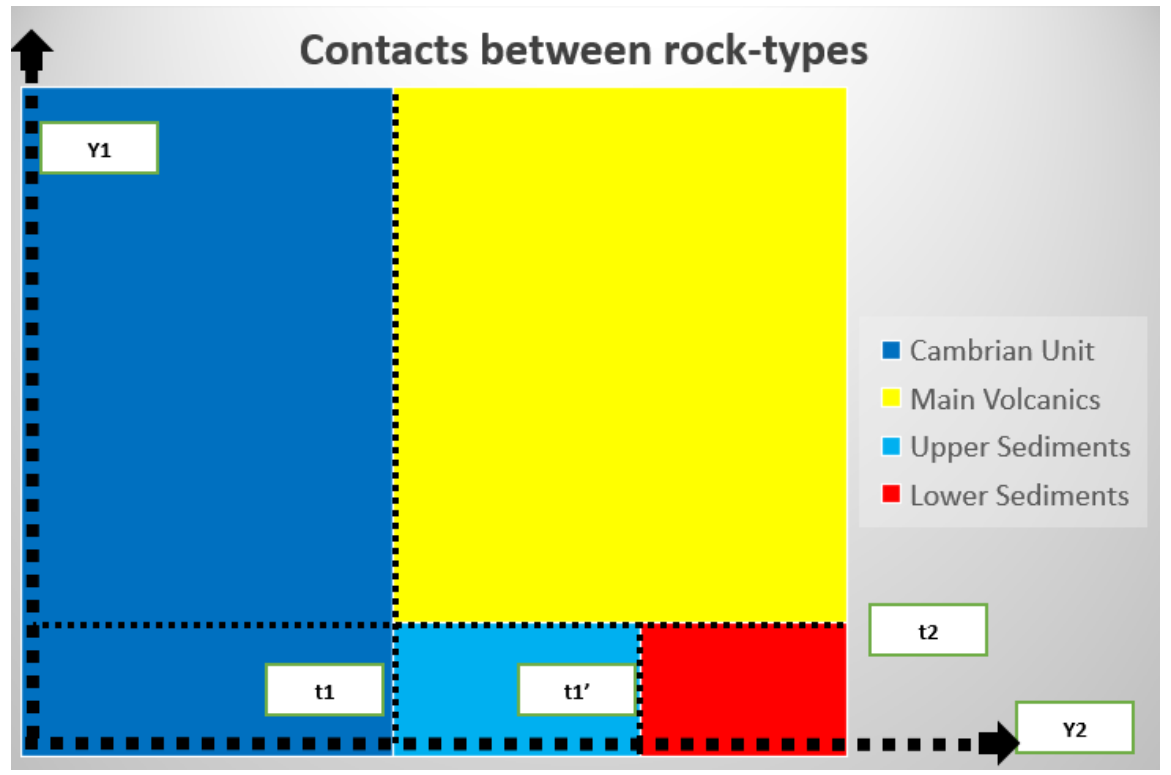

Figure 51 Truncation rule with thresholds along $\left(Y_{1}\right.$ and $\left.Y_{2}\right)$ fields

With the thresholds included to fully define the spatial characteristics of all the rock-types, the relationship between the indicators and these GRFs can be expressed as:

$$
\operatorname{ICAM}(x)=\left\{\begin{array}{c}
1 \text { if } Y_{2}(x)<t_{1}(x) \\
0 \text { otherwise }
\end{array}\right.
$$

$$
\begin{aligned}
& \operatorname{IUPS}(x) \\
& =\left\{\begin{array}{c}
1 \text { if } Y_{2}(x) \geq t_{1}(x) \text { and } Y_{2}(x)<t_{1}{ }^{\prime}(x) \text { and } Y_{1}(x)<t_{2}(x) \\
0 \text { otherwise }
\end{array}\right.
\end{aligned}
$$

$$
\operatorname{IMVC}(x)=\left\{\begin{array}{c}
1 \text { if } Y_{2}(x) \geq t_{1}(x) \text { and } Y_{1}(x) \geq t_{2} \\
0 \text { otherwise }
\end{array}\right.
$$

$$
\operatorname{ILSS}(x)=\left\{\begin{array}{c}
1 \text { if } Y_{2}(x) \geq t_{1}^{\prime}(x) \text { and } Y_{1}(x)<t_{2}(x) \\
0 \text { otherwise }
\end{array}\right.
$$


The thresholds values depend on the proportions of each rock-type, and in each Gaussian random field range from -3 to 3 . Because the sum of the indicators is equal to one, at any point within the fields, the sum of all the four rock-types should be one, meaning the proportions should be CAM (0.45), UPS (0.06), MVC (0.44) and LSS (0.05). The variance of an indicator is a function of its mean because the square of an indicator is equal to itself and therefore the spatial averages of the indicators is the average probability which represents each rock-type (Betzhold and Roth, 2000). To calculate the thresholds, for example, if we want to determine the threshold $\left(t_{1}\right)$ in Eq. (10) for truncating Cambrian rocks, the relationship can be expressed as;

$$
\begin{gathered}
E(\operatorname{Icam})=\operatorname{pr}\left(Y_{2}(x)<t_{1}=f\left(t_{1}\right)\right. \\
t_{1}=f^{-1}(\mathrm{P} \text { cam })=f^{-1}(0.45)
\end{gathered}
$$

Where $\operatorname{pr}\left(Y_{2}(x)\right.$ denotes the mean of the Cambrian rock indicator and $f$ is the standard cumulative distribution functions and Pcam is the probability of the proportion of Cambrian rocks. The means of the other indicators are calculated the same way and the determined threshold $\left(t_{1}\right)$ is used together with inverted Eq. (11-13) to calculate the other thresholds $\left(t_{1}{ }^{\prime}\right.$ and $\left.t_{2}\right)$.

The following thresholds which represent the truncation rule are then determined at $t_{1}=$ $-0.1348, t_{1}{ }^{\prime}=0.6588$ and $t_{2}=-0.8600$. Figure 5 indicates two axes of underlying Mutli-Gaussian fields $\left(Y_{1}\right.$ and $\left.Y_{2}\right)$ with each axes having a mean of 0 and a variance of 1 . The four rock-types are truncated according the rock-type rule presented in the Eq. (10 13). Eq. (10) shows that Cambrian rocks are truncated along $Y 2$ and should belong to values less the threshold $t_{1}$ while the other three rocks-types depend on the interaction between both $\left(Y_{1}\right.$ and $\left.Y_{2}\right)$, and their thresholds. Therefore, this relationship enables simulations of these rocks types once their spatial variograms are determined because the position in space of individual rock-types is already determined through this Pluri-Gaussian model. 


\subsubsection{Variogram analysis and spatial dependence modeling}

With the truncation rule governing the spatial relationship between the rock-types evaluated, modeling their GRFs variograms is the next step. This is achieved through modeling the proposed Gaussian Random Fields $\left(Y_{1}\right.$ and $\left.Y_{2}\right)$, by trial and error fitting of the experimental indicator and experimental cross variograms between indicator and grade with the desired covariance model. In our case, we assumed the Gaussian random fields to be dependent, and therefore their cross variograms parameters are also defined together with other model parameters. To fully map out the cross-correlation between the $\operatorname{GRF}\left(Y_{0}\right)$ and the other two GRF's $\left(Y_{1}\right.$ and $\left.Y_{2}\right)$, the assumption is that the two exponential structures of $Y_{1}$ are present in both $Y_{0}$ and $Y_{2}$ and the same for $Y_{2}$. These two underlying GRFs are both influenced by the first $\operatorname{GRF}\left(Y_{0}\right)$, hence adopt its basic nested structures; eventually we determined the variograms shown in Figure 6 that define the Pluri-Gaussian model as shown below.

$$
\begin{gathered}
\gamma_{11}=0.00 \text { nugget }+0.20 \exp (307,202,120) m \\
+0.80 \exp (750,750,165) m
\end{gathered}
$$




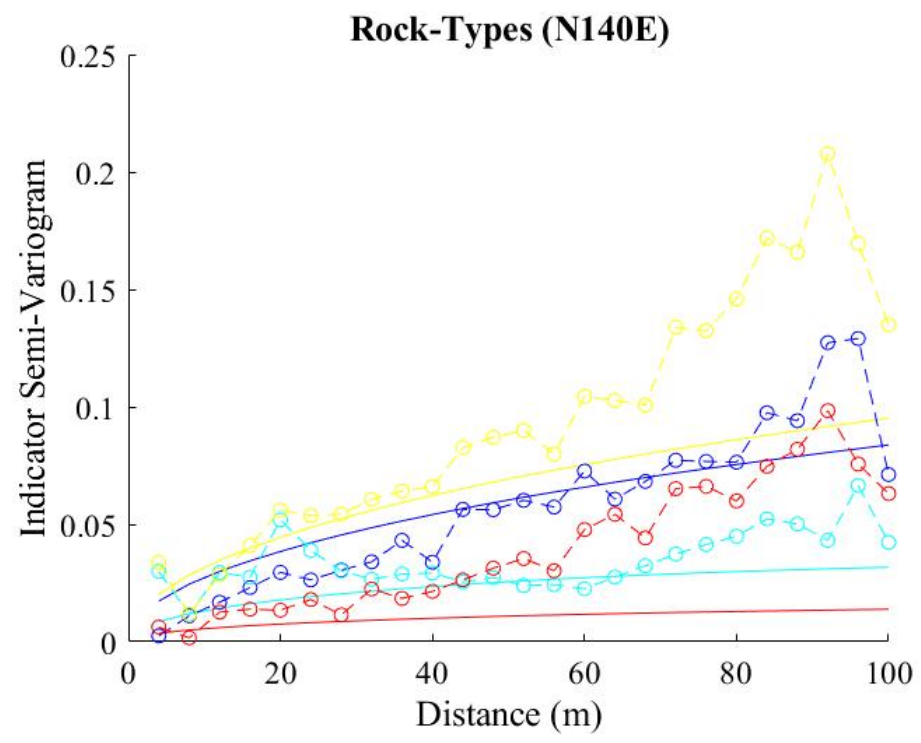

\begin{tabular}{|l|l|}
\hline \multicolumn{2}{|c|}{ Legend } \\
\hline CAM & \\
\hline UPS & \\
\hline MVC & \\
\hline LSS & \\
\hline
\end{tabular}

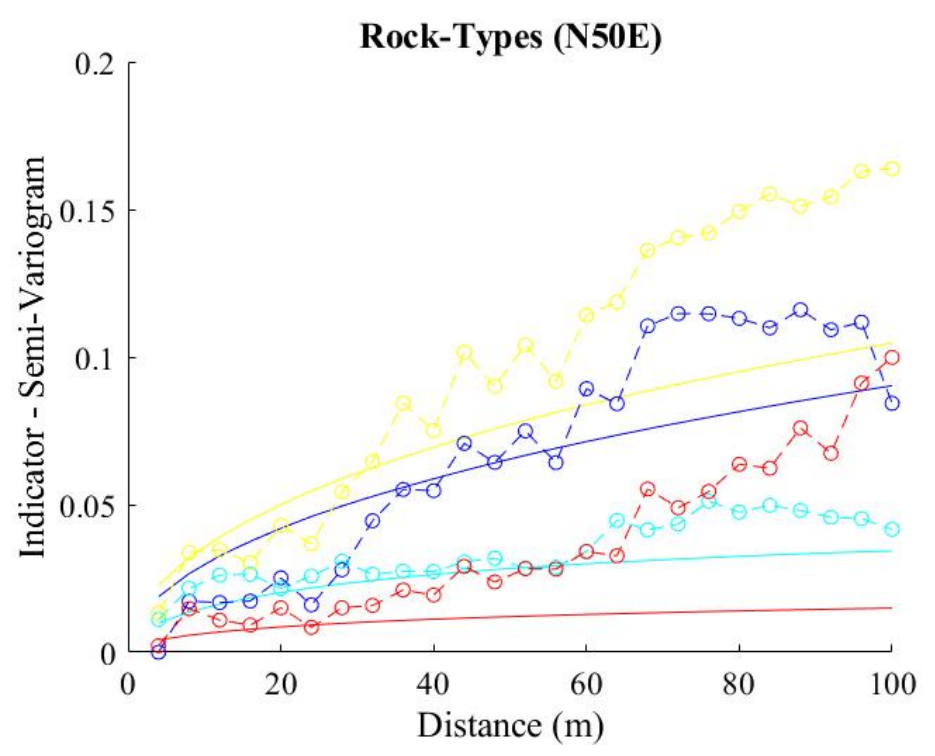

\begin{tabular}{|l|l|}
\hline \multicolumn{2}{|c|}{ Legend } \\
\hline CAM & \\
\hline$U P S$ & \\
\hline$M V C$ & \\
\hline LSS & \\
\hline
\end{tabular}




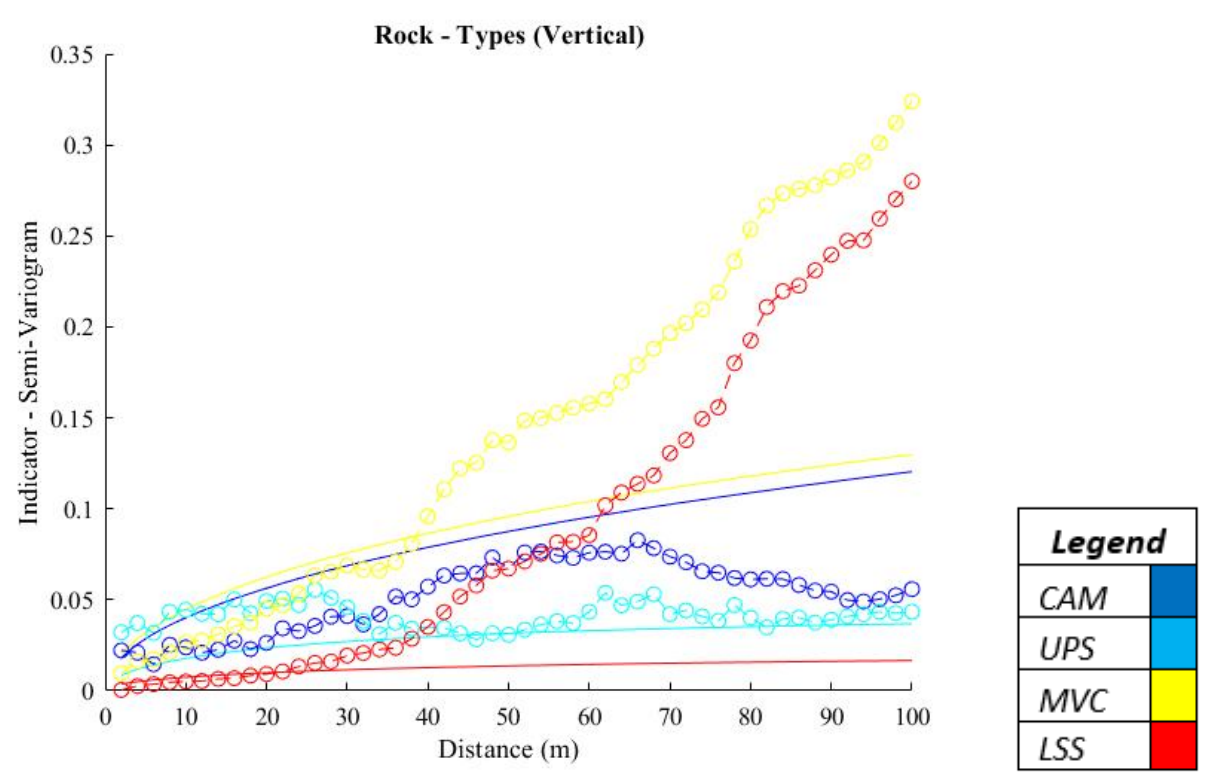

Figure 61 Indicator variograms in three anisotropy directions (circles are experimental variograms \& solids are models)

With all the GRFs $\left(Y_{0}, Y_{1}\right.$ and $\left.Y_{2}\right)$ determined, their spatial dependence is addressed through identifying their model structures. The exponential structure is common to all GRF, and the cross-correlation between all the fields is investigated through a linear model of the GRF's coregionalization, as indicated in Eq. (16-17). In the coregionalization matrices, diagonal entries represent the direct variograms of $Y_{0}, Y_{1}$ and $Y_{2}$, and the offdiagonal entries reflect the cross variograms between $Y_{0}, Y_{1}$ and $Y_{2}$ which results in Figure 7 variograms. The cross variogram between $Y_{0}$ and $Y_{1}$ is captured by coefficients $\mathrm{d}$ and a. $Y_{0}$ and $Y_{2}$ by coefficients e and $\mathrm{c}$ and $Y_{1}$ and $Y_{2}$ by coefficients 1 and $\mathrm{j}$. The structure of GRF $Y_{1}$ is characterized by entries $\mathrm{c} 1$ and $\mathrm{b} 1$ which represent its sills and a nugget of 0 while GRF $Y_{2}$ is characterized by entries $\mathrm{c} 2$ and b2 which are sills also with a 0 nugget. Both these fields are supposed to sum up to one and also all the coregionalization matrices should be positive semi-definite since their eigenvalues are nonnegative (Wachernagel, 2003). The results of the coefficients while doing the trial and error method are summarized in Table 3. 

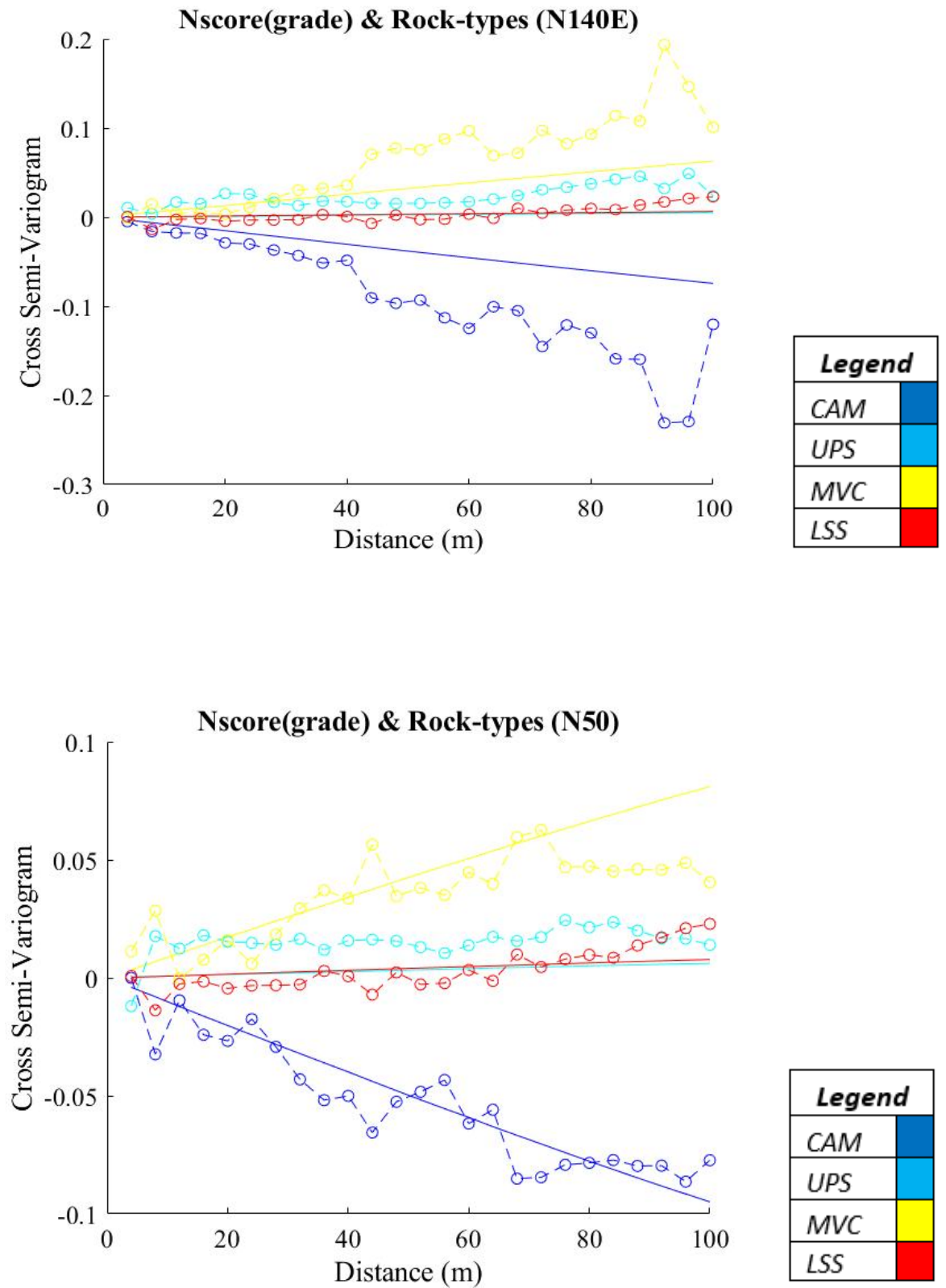


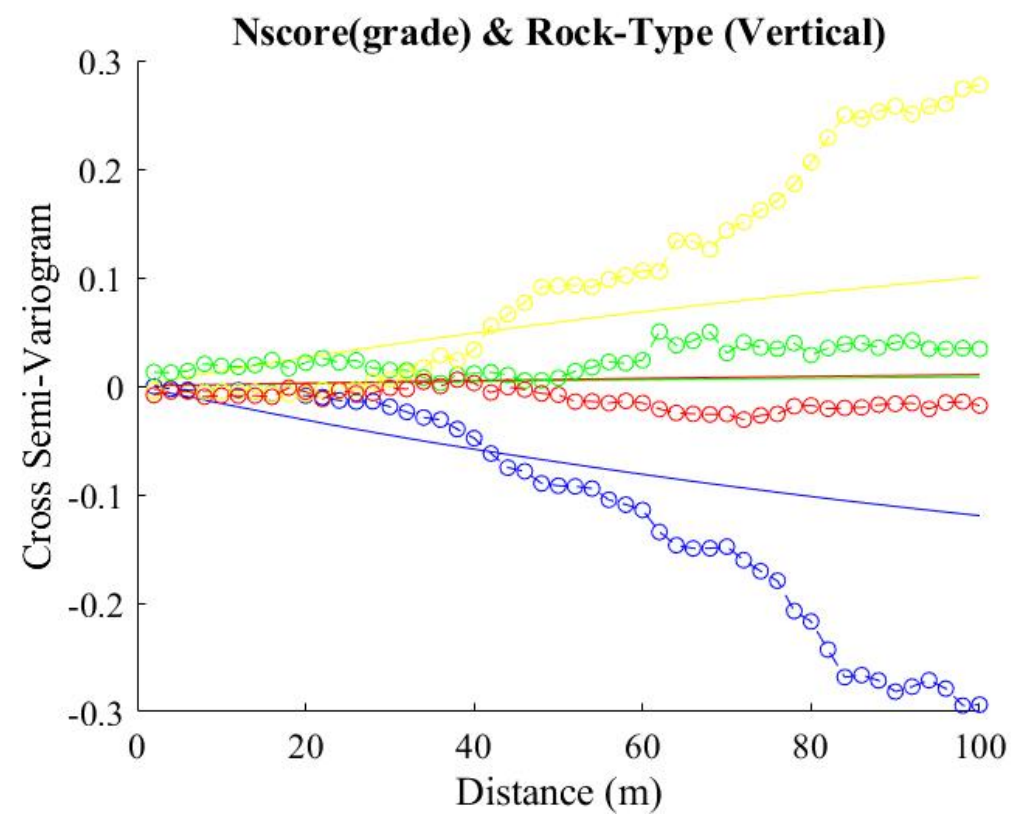

\begin{tabular}{|l|l|}
\hline \multicolumn{2}{|c|}{ Legend } \\
\hline CAM & \\
\hline UPS & \\
\hline MVC & \\
\hline LSS & \\
\hline
\end{tabular}

Figure 71 Cross variograms between indicator and grade in three anisotropy directions (circles are experimental variograms \& solids are models)

As we have already discussed in the truncation rule (Pluri-Gaussian model), we have completely determined which Gaussian Random Fields and thresholds are responsible for modeling which rock-type, and we have also determined their spatial contribution (dependence) in modeling rocks-types with grades. The CAM was found to be truncated along the GRF $Y_{2}$, for which the sill contribution of its first nested structure (0.70) has a higher variability in shorter distances along the main anisotropies as compared to its second nested structure (0.30) with lower variability in longer ranges along the same anisotropies. Moreover, the auto-correlation of the CAM and grades is found to be stronger in shorter distances. The same is observed for the other three-rock-types but their variability is mainly determined by all the thresholds since they depend on both GRF $Y_{1}$ and $Y_{2}$. These rocktypes spatial auto-corroletion grade will be controlled by the coefficients in coregionalization model. 


$$
\begin{aligned}
& \left(\begin{array}{lll}
\gamma 00 & \gamma 01 & \gamma 02 \\
\gamma 01 & \gamma 11 & \gamma 12 \\
\gamma 02 & \gamma 12 & \gamma 22
\end{array}\right)=\operatorname{nugget}\left(\begin{array}{ccc}
0.4 & 0 & 0 \\
0 & \mathrm{a} 1 & 0 \\
0 & 0 & \mathrm{a} 2
\end{array}\right)+ \\
& \exp \left(\begin{array}{ccc}
0.4 & d & e \\
d & c 1 & j \\
e & j & c 2
\end{array}\right)(307,202,120) m+ \\
& \exp \left(\begin{array}{ccc}
0.2 & a & c \\
a & b 1 & l \\
c & l & b 2
\end{array}\right)(750,750,135) m
\end{aligned}
$$

Table 31 Parameters from trial and error coregionalization model

\begin{tabular}{|c|l|l|l|l|l|l|}
\hline Model & \multicolumn{2}{|c|}{ Nugget } & \multicolumn{2}{c|}{ Structure 1 } & \multicolumn{2}{c|}{ Structure 2 } \\
\hline \multirow{5}{*}{ Parameter } & a1 & 0 & c1 & 0.20 & b1 & 0.80 \\
\cline { 2 - 8 } & a2 & 0 & c2 & 0.70 & b2 & 0.30 \\
\cline { 2 - 8 } & & & d & 0.25 & a & 0.35 \\
\cline { 2 - 7 } & & & e & 0.05 & c & 0.01 \\
\cline { 2 - 7 } & & & $\mathrm{j}$ & 0.15 & 1 & 0.20 \\
\hline
\end{tabular}

\subsubsection{Joint simulation results}

\subsubsection{Co-simulation \& realizations}

From the coregionalization model, all the Gaussian Random Fields can be simulated together since they are in one format-structure. Data locations of the two GRF $\left(Y_{1}\right.$ and $\left.Y_{2}\right)$ are then simulated conditionally to the grade and rock type data via a Gibbs sampler algorithm. This enables joining all these GRF's $\left(Y_{0}, Y_{1}\right.$ and $\left.Y_{2}\right)$, through a Multi-Gaussian simulation algorithm such as the turning bands which is used. Eventually, a back transformation algorithm is used to back transform normal score data to gold grade; the truncation rule, defined in Eq. (10-13), is used to transform indicator data back to rocktype, thus creating multiple realizations of each variable as in Figure 8 and 9. A set of 25 realizations are produced for continuous (grade) variable together with corresponding 25 realizations for the categorical variable (rock-types). 

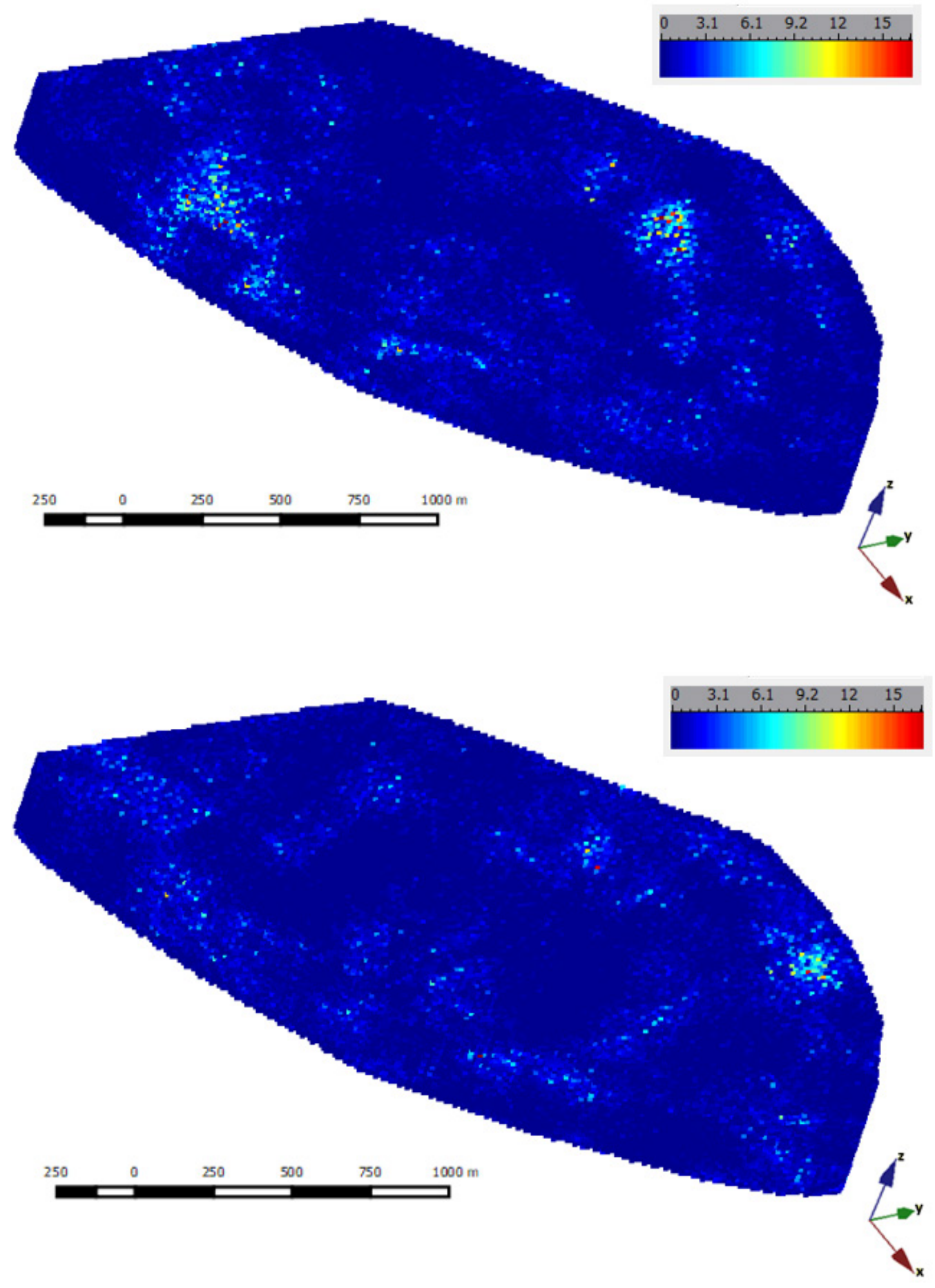

Figure 81 Random grade realizations generated from the joint simulation 
The joint simulation enabled us to determining how the grades change with changing rocktypes. While looking at the realization maps, the joint simulation produces gradual or rather smooth transitions of gold grades across rock-types. The observation from multiple realizations of grade indicated various probabilities of gold concentration within the deposit as shown by changing high grade areas in the random realizations in Figure 8 . This is important because it provides a level of uncertainty since each image show unique grade distributions within the deposit for which the true grade can fall within.

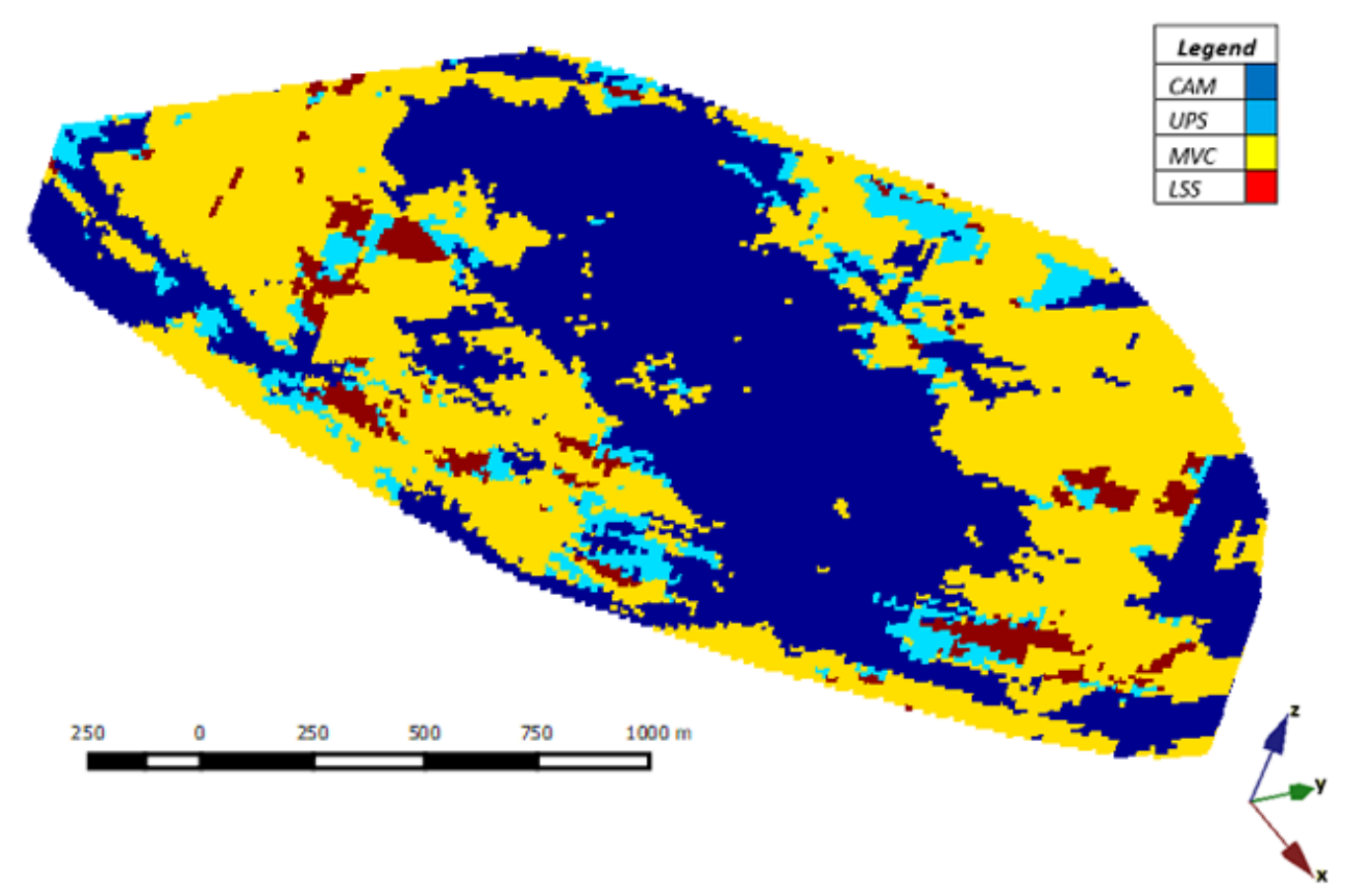




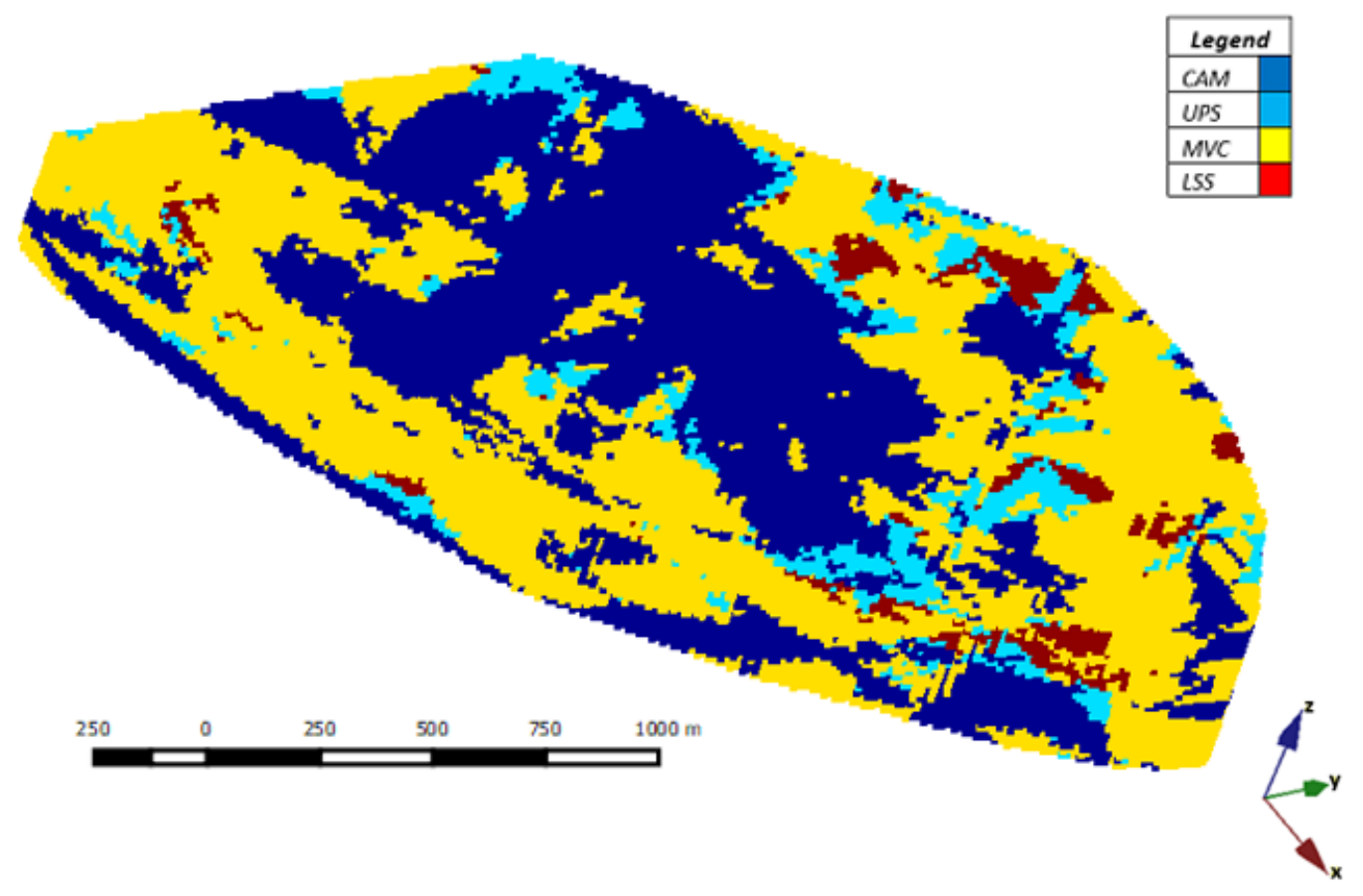

Figure 91 Random rock-type realizations generated from the joint simulation

Another observation from the rock-types realizations is that there are various possibilities of rock-type distribution which will be vital for evaluating tonnages (volumes) especially if mineralization prefers as certain rock-type. This is a scenario in our case study deposit where grade is hosted mainly in UPS, MVC and LSS rock-types and not in CAM. Tonnage, grades and metal content uncertainty are critical in evaluating resources and reserves and therefore the multiple simulations can be used to provide a measure of uncertainty within a resource model.

\subsubsection{Validation of the Joint Simulation Models}

For validating the continuous variable (grade) simulation, histograms and experimental variograms from generated simulations are plotted and compared with the composite gold grade from the drill hole data. The histogram distributions for the realizations indicates that they reflect the original data reasonably as shown in figure 10. The experimental variograms in the three principal axes, also indicate the spatial nature of the original data is preserved in the simulation as shown in figure 11. 


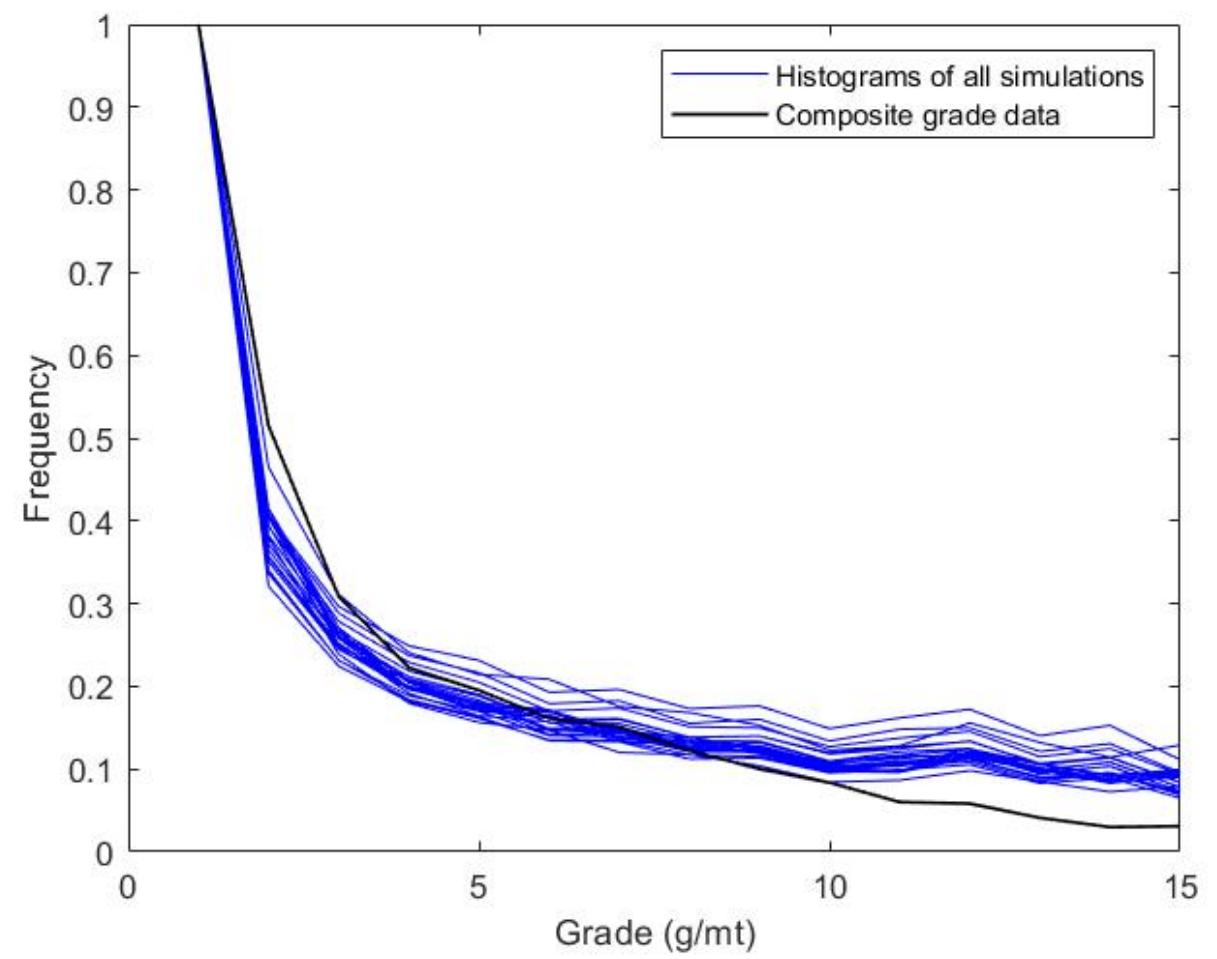

Figure 101 Histograms of simulated gold grades and composite grade from drill-hole data

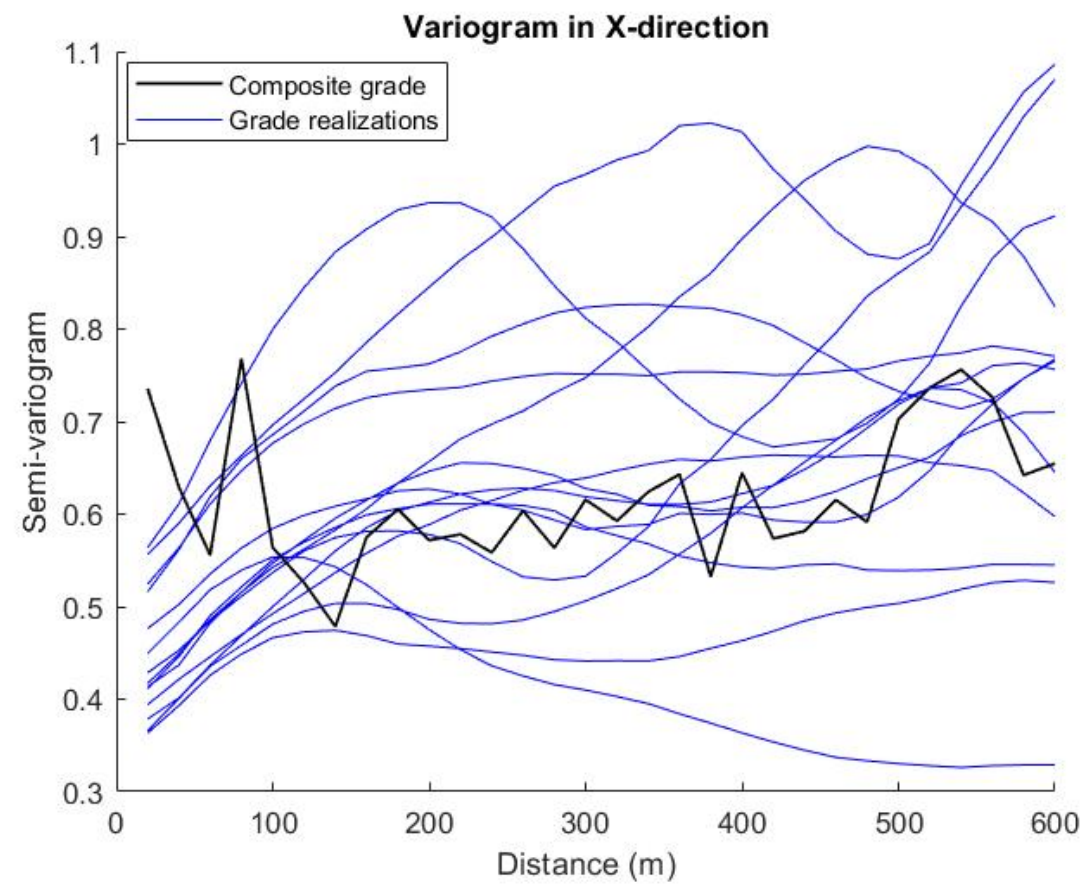



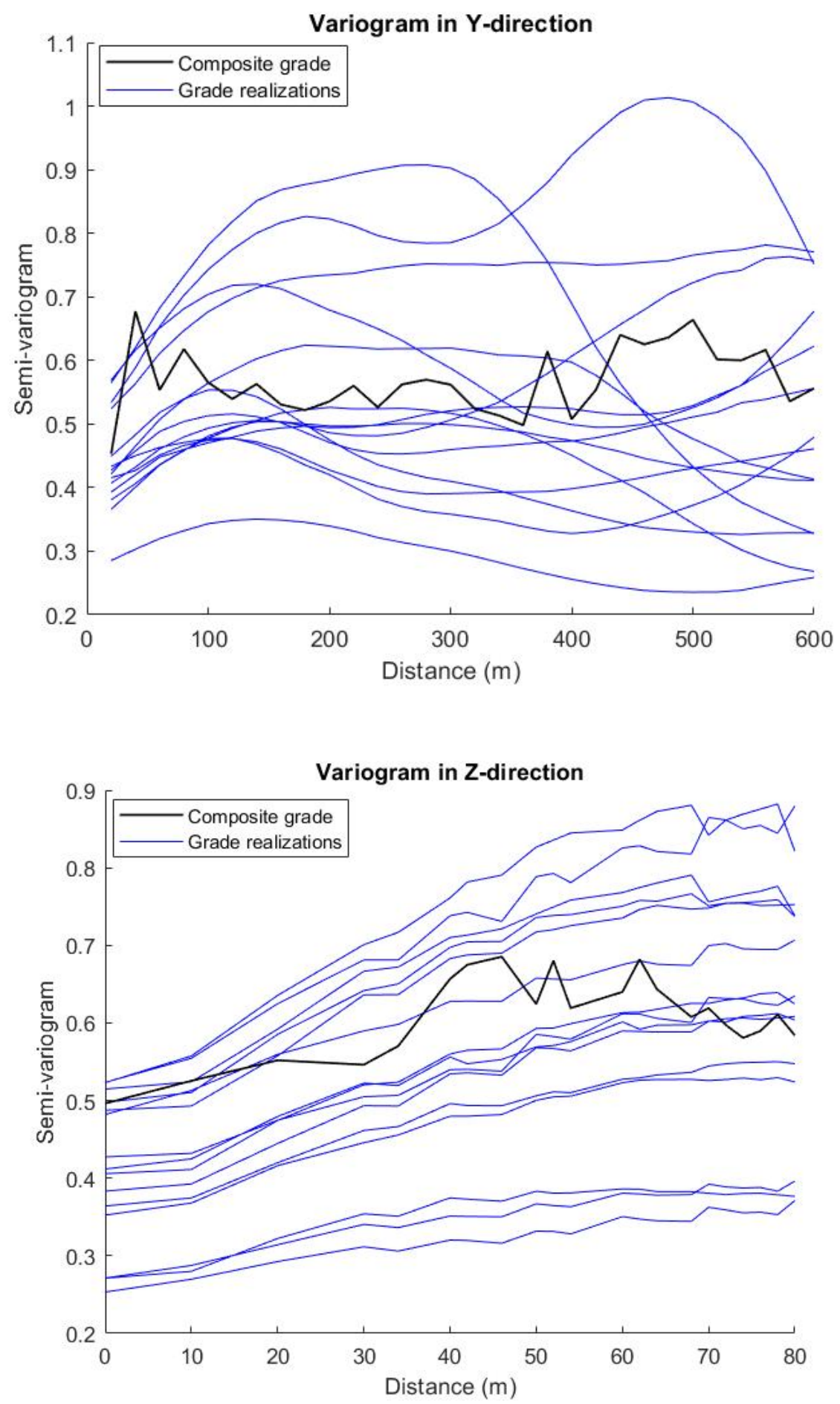

Figure 111 Variograms of simulated gold grades in $X$-direction, $Y$-direction and Zdirection compared with composite gold grades 
For the simulated rock-types, the generated realizations are validated through a box plot and conditioning drill hole data in a three-dimensional space shown in Figures 13. Respectively, the rock-types statistics are well preserved in the simulated realizations and also in the drill hole rock-type data. A noticeable difference between CAM and MVC proportions could be due to fitting of the indicator variograms where the sill contribution in the horizontal direction are weighted more for MVC than the CAM.
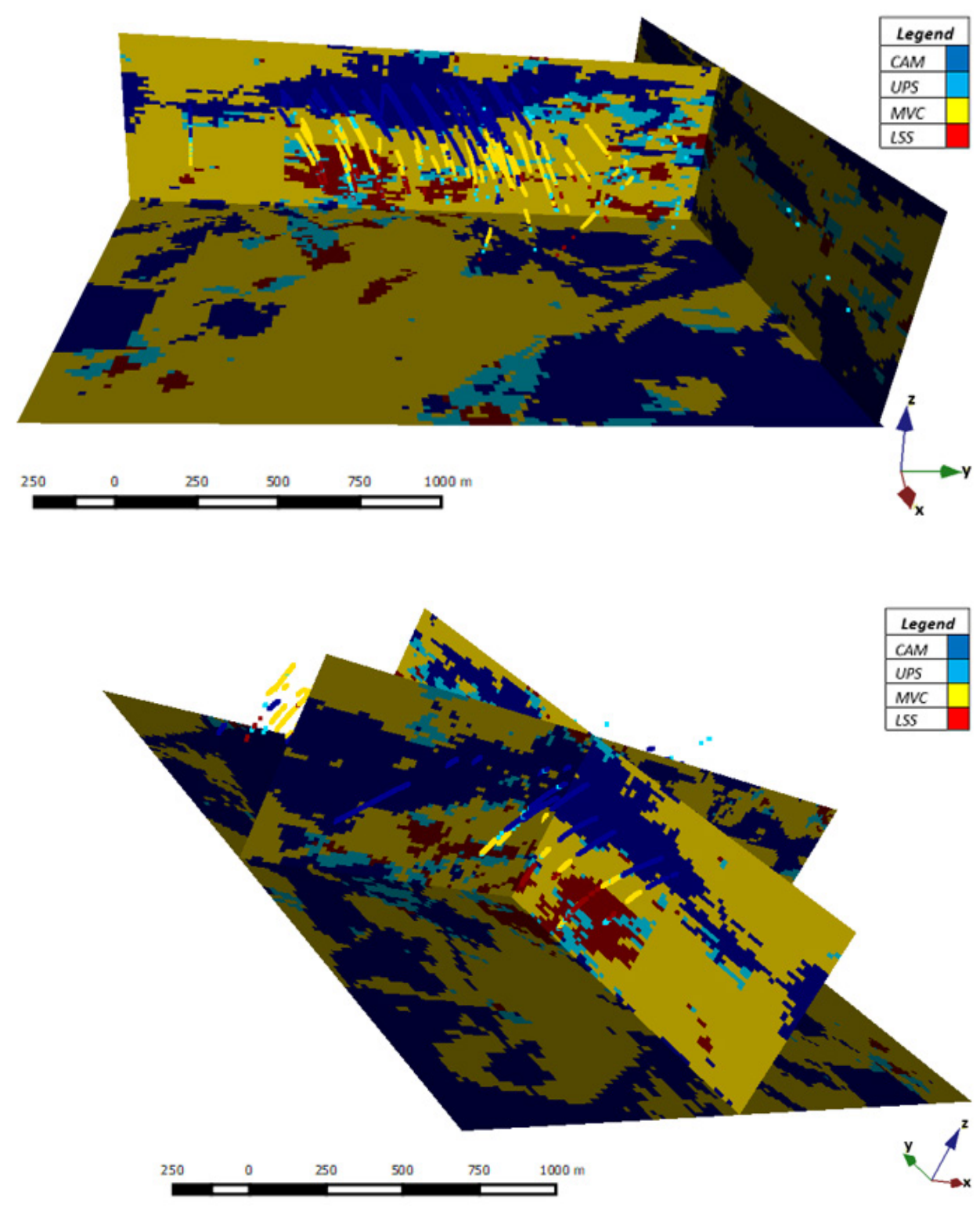

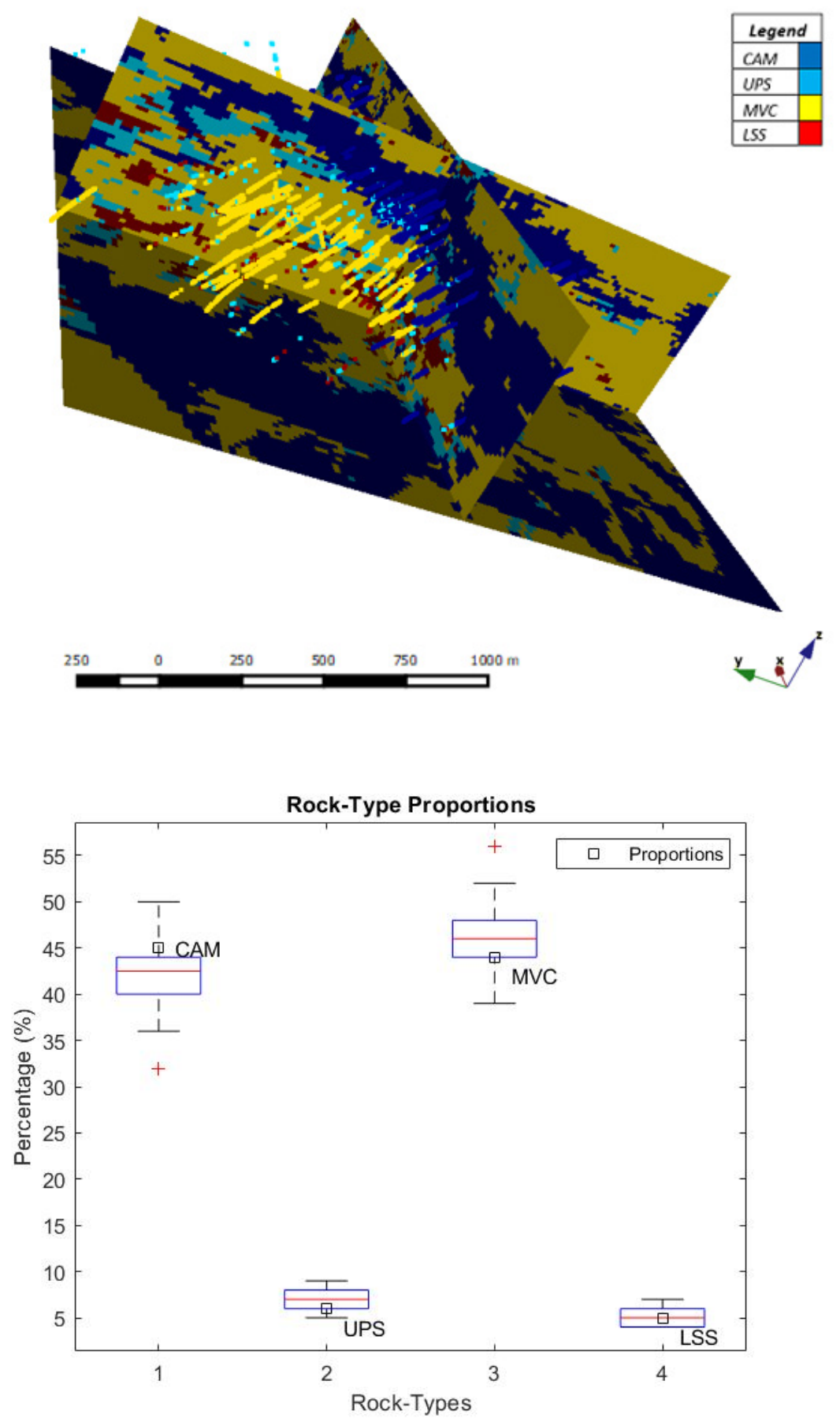

Figure 121 Drill holes conditioned to rock-types (before topographic removal) and box plot of all 25 realizations of rock-type proportions 


\subsubsection{Resource classification}

Post-processing of the grade realizations produced E-type (mean), conditional variance and relative conditional maps respectively as shown in Figure 13. From the E-type map, the high grade areas indicate high values of conditional variance while the low grade areas show low values of conditional variance. This observed directly proportional relationship between variance and grade in our resource model implies that we have relatively low confidence on high grade blocks and vice-versa for low grade blocks. To understand the deposit better, relative conditional variance map is generated by dividing the E-type map with the square of conditional variance map. This map shows a rather uniform distribution of variance on both high and low grade blocks. The relative conditional variance therefore provides us with an opportunity to classify the resources more confidently.

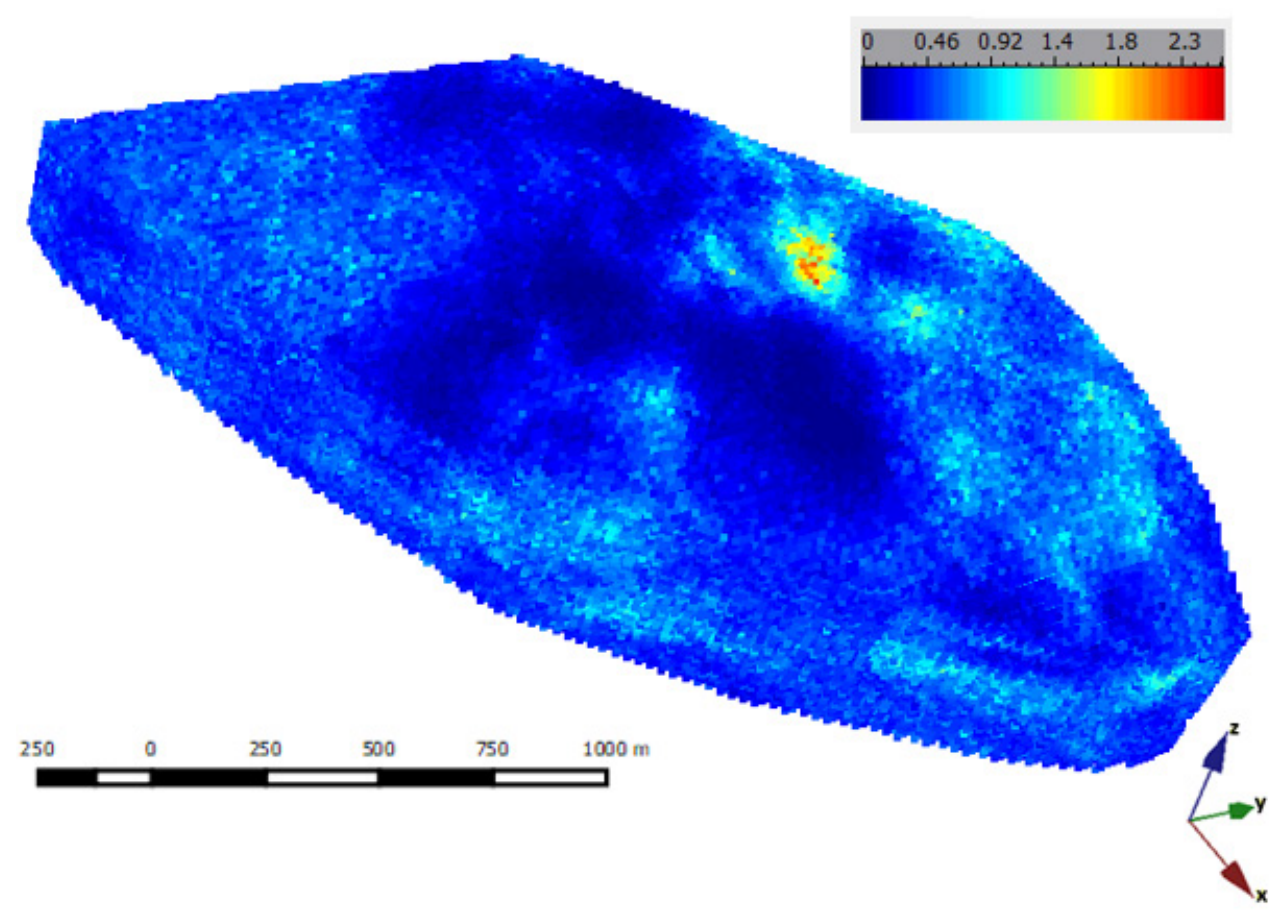



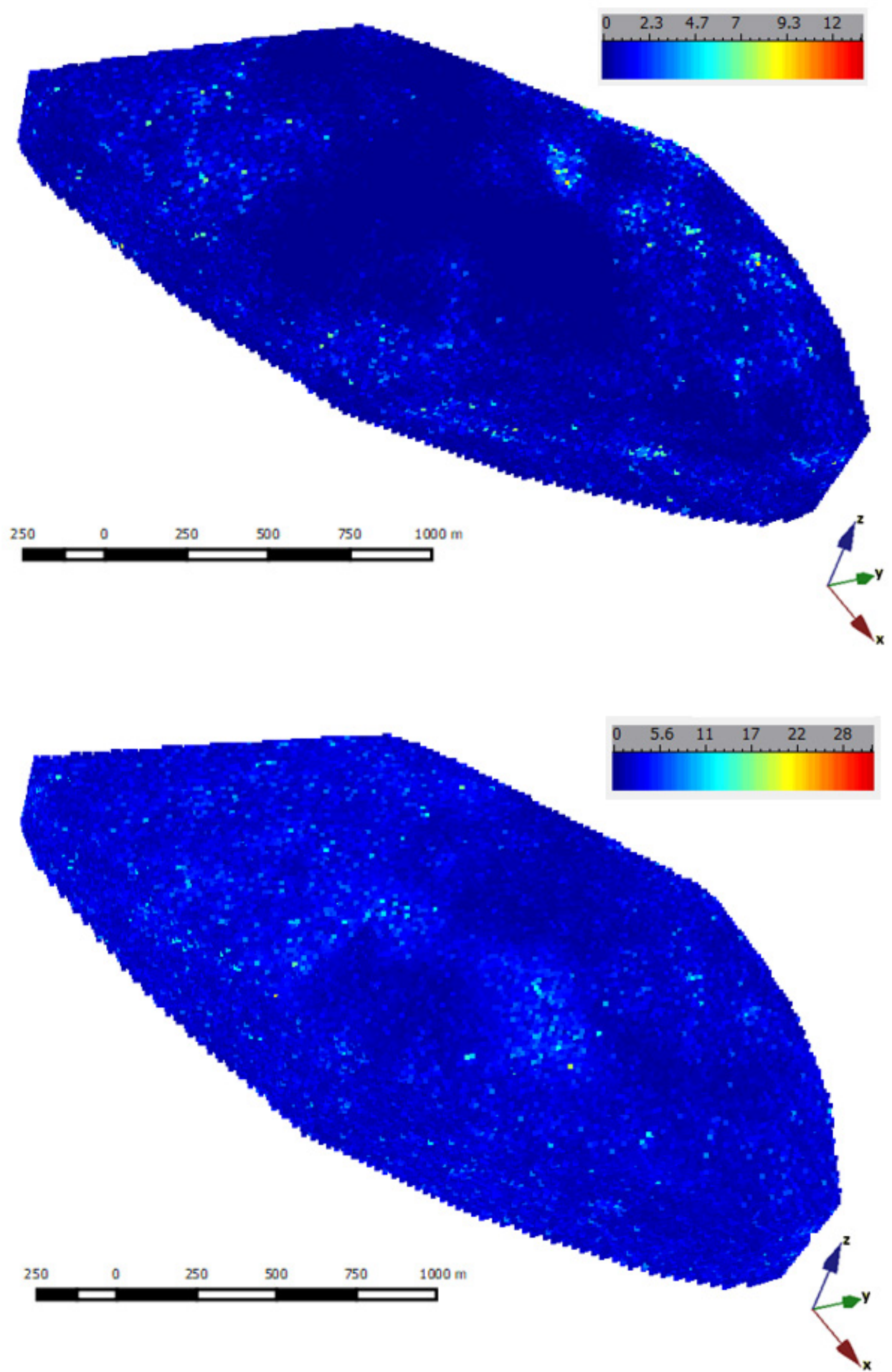

Figure 131 E-type and Conditional Variance and Relative Conditional Variance Maps of simulated gold grades 
To obtain the resource classification scheme of our resource model, relative conditional variance is used and is preferred because it doesn't show any preference to high or low grade areas in a deposit because the ratio between the dispersion indicator and the mean are found in the intervals $(0,1)$ (Chiles and Delfiner, 1999). Thresholds are then selected as inputs to classify the resource into three categories (measured, indicated and inferred). The relative conditional variance range is between $0-13.07 \mathrm{~g} / \mathrm{mt}$ and the threshold values were selected from this range. For classifying measured resources, the threshold is determined on the basis of less than $5 \%$ of the range from the relative conditional variance map. The indicated resources are classified with a threshold from 5 to $10 \%$ of the range also from the relative conditional variance map, while anything above $10 \%$ of this range is considered as inferred resources.

Table 41 Resource classification (Mmt=Million metric tonnes. Koz=thousands of ounces)

\begin{tabular}{|l|c|c|c|}
\hline $\begin{array}{l}\text { Resource } \\
\text { Classification }\end{array}$ & Tonnes $(\mathbf{M m t})$ & Au (g/mt) & $\begin{array}{l}\text { Metal content } \\
\text { (Koz) Au }\end{array}$ \\
\hline Measured (M) & 294.8 & 0.6142 & $5,821.1$ \\
\hline Indicated (I) & 518.4 & 0.5197 & $8,661.2$ \\
\hline Total M+I & $\mathbf{8 1 3 . 2}$ & $\mathbf{0 . 5 5 3 9}$ & $\mathbf{1 4 , 4 8 2 . 2}$ \\
\hline Inferred & $1,076.0$ & 0.4972 & $17,201.3$ \\
\hline Grand Total & $\mathbf{1 , 8 8 9 . 1}$ & $\mathbf{0 . 5 2 1 7}$ & $\mathbf{3 1 , 6 8 3 . 5}$ \\
\hline
\end{tabular}

Because the resource classification is only done on an average, for example, E-type, uncertainty in this estimation procedure is eminent due to one solution being provided. To quantify the overall resources so that we can have an idea of our grades, tonnages and metal content, the realizations generated from the joint simulation are used for conditional simulation of the grades and therefore for estimating blocks within our resource model. This provides a logical approach as each grade realization represents a possible reality of the distribution of grades, tonnages and metal content and therefore summarizes the total amount of material within the deposit (Emery et al., 2006). Another advantage of using 
conditional simulation for uncertainty is that various cut-offs can be used without having to evaluate the whole deposit, but this was beyond the scope of this thesis.

Table 51 Summary of tonnage, grade and metal content uncertainty using joint simulation

\begin{tabular}{|c|c|c|c|}
\hline $\begin{array}{c}\text { Joint } \\
\text { Simulation }\end{array}$ & Tonnage (Mmt) & $\begin{array}{c}\text { Grade g/mt } \\
\mathbf{A u}\end{array}$ & $\begin{array}{c}\text { Metal Content } \\
\text { (Koz) }\end{array}$ \\
\hline Simulation 1 & $1,889.1$ & 0.5098 & $30,963.8$ \\
\hline Simulation 2 & $1,889.1$ & 0.4856 & $29,495.3$ \\
\hline Simulation 3 & $1,889.1$ & 0.5364 & $32,580.5$ \\
\hline Simulation 4 & $1,889.1$ & 0.5325 & $32,338.8$ \\
\hline Simulation 5 & $1,889.1$ & 0.5085 & $30,885.6$ \\
\hline Simulation 6 & $1,889.1$ & 0.4914 & $29,842.7$ \\
\hline Simulation 7 & $1,889.1$ & 0.4831 & $29,342.2$ \\
\hline Simulation 8 & $1,889.1$ & 0.4985 & $30,276.6$ \\
\hline Simulation 9 & $1,889.1$ & 0.5926 & $35,992.6$ \\
\hline Simulation 10 & $1,889.1$ & 0.4993 & $30,322.9$ \\
\hline Simulation 11 & $1,889.1$ & 0.4527 & $27,496.5$ \\
\hline Simulation 12 & $1,889.1$ & 0.5284 & $32,094.5$ \\
\hline Simulation 13 & $1,889.1$ & 0.4854 & $29,482.8$ \\
\hline Simulation 14 & $1,889.1$ & 0.4700 & 28.543 .9 \\
\hline Simulation 15 & $1,889.1$ & 0.5335 & $32,402.7$ \\
\hline Simulation 16 & $1,889.1$ & 0.5335 & $32,407.7$ \\
\hline Simulation 17 & $1,889.1$ & 0.5149 & $31,271.9$ \\
\hline Simulation 18 & $1,889.1$ & 0.4986 & $30,283.6$ \\
\hline Simulation 19 & $1,889.1$ & 0.5957 & $36,180.6$ \\
\hline Simulation 20 & $1,889.1$ & 0.4158 & $25,253.2$ \\
\hline Simulation 21 & $1,889.1$ & 0.6479 & $39,347.9$ \\
\hline Simulation 22 & $1,889.1$ & 0.4406 & $26,757.5$ \\
\hline Simulation 23 & $1,889.1$ & 0.4821 & $29,277.2$ \\
\hline Simulation 24 & $1,889.1$ & 0.4821 & $29,277.2$ \\
\hline Simulation 25 & $1,889.1$ & 0.5489 & $33,335.6$ \\
\hline & & & \\
\hline
\end{tabular}

The grades, tonnage and metal content uncertainties are summarized in Table 5. The grade estimates from the joint simulation show various average grades in the range of 0.4158 to $0.6479 \mathrm{~g} / \mathrm{mt}$ and an average grade of $0.5107 \mathrm{~g} / \mathrm{mt}$. The average grade estimate from the measured and indicated resources shown in table $4 ; 0.6142$ and $0.5197 \mathrm{~g} / \mathrm{mt}$ respectively, 
lie within the uncertainty range which provides confidence in the estimation. This is important because some resource estimation methods can be less representative of the resource and if simulations are available, they can be used as another form of check if the results make some sense.

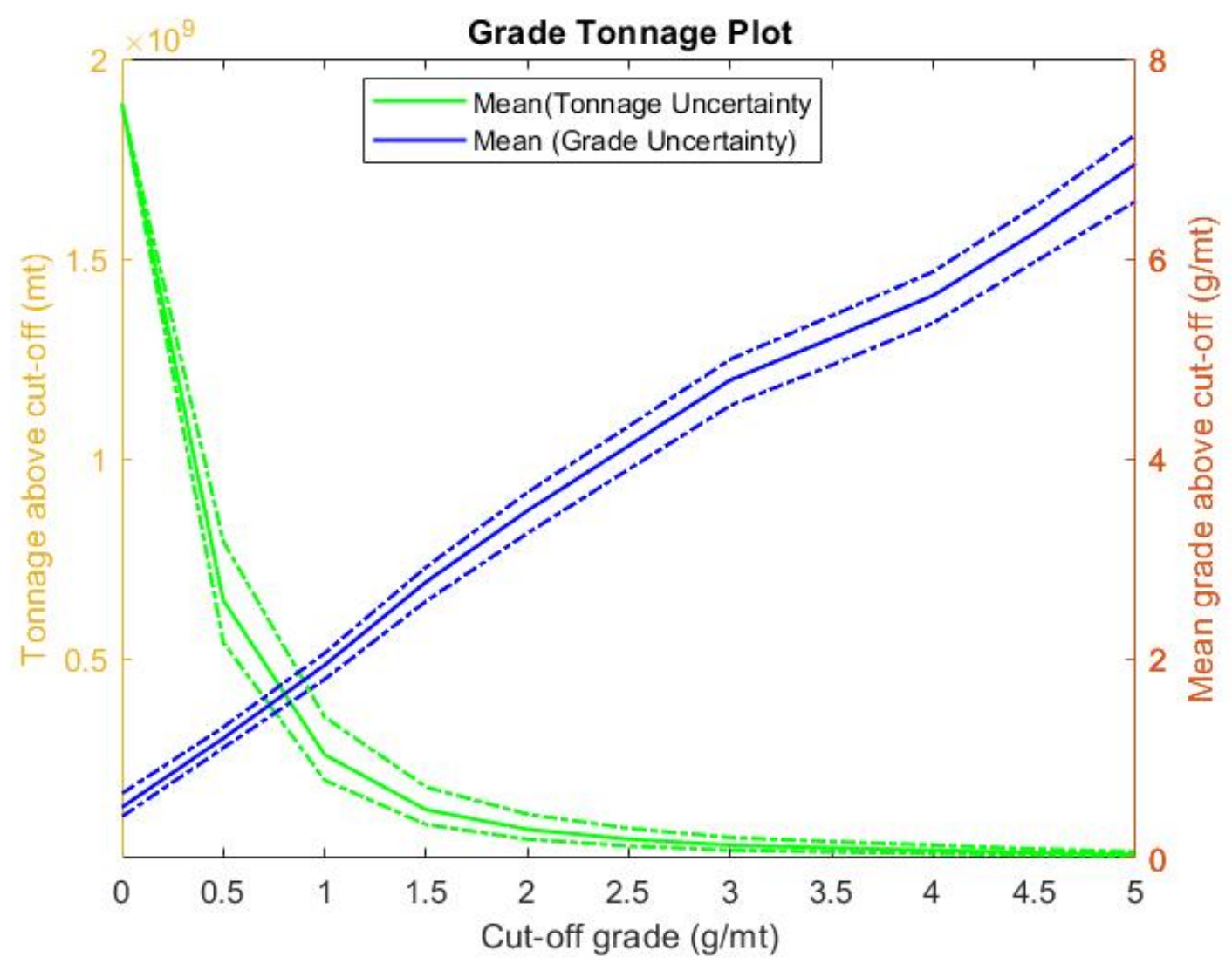

Figure 141 Grade tonnage curve showing mean, upper limit and lower limit uncertainty for tonnage and average grade of all the simulation

The tonnage curve shown in Figure 14 shows the mean grade uncertainty above cut-off grade of all the 25 simulations with upper and lower limits (blue dashed lines) and the mean tonnage uncertainty also with upper and lower limits (green dashed lines). From the tonnage curve, at lower cut-off grades, the differences between the upper limit and lower limit of the average grades is minimal and this difference increases as the cut-off grade increases. This observation can be used to analyse risk; at lower cut-off grades, we are more confident of our resource model than at higher cut-off grades. Moreover, if we 
consider a cut-off grade at $0.5 \mathrm{~g} / \mathrm{mt}$, we get approximately $700 \mathrm{Mmt}$ at an average grade of $1.4 \mathrm{~g} / \mathrm{mt}$ for 31.5 million ounces of gold and compare with a cut-off grade at $0.8 \mathrm{~g} / \mathrm{mt}$, for approximately $400 \mathrm{Mmt}$ at an average grade of $1.7 \mathrm{~g} / \mathrm{mt}$ for 21.9 million ounces of gold, we can see that our resource model might be sensitive to cut-off grade. At this point, the tonnage curve only shows the characteristics of the deposit without economic viability of the mineable part of the deposit which is addressed in the next section of recoverable reserve calculations.

\subsubsection{Reserve calculations}

The recoverable calculations were based on the multiple grade simulations generated from the joint simulation. The selected blocks represent the measured and indicated resources determined through resource classification scheme of the resource model. The process of pit optimization using the Maximum Flow algorithm is intended to select blocks that can or cannot be mined while respecting the slope constraint while providing maximum returns on profit. A summary of economic parameters used as inputs for reserve calculation is provided in Table 6. These parameters are used to calculate the block economic value for each block and the gold price that is used is an average of 3 months while other parameters are standardized. For the slope calculation, all the blocks were used including blocks from the inferred resources.

Table 61 Economic parameter inputs for calculation of mineable blocks

\begin{tabular}{|c|c|c|}
\hline Parameter & Unit & $\begin{array}{c}\text { Measured \& Indicated } \\
\text { Resource }\end{array}$ \\
\hline Specific gravity & $\mathrm{m}^{3} / \mathrm{g}$ & 2.7 \\
\hline Recovery & $\%$ & 100 \\
\hline $\begin{array}{c}\text { Selling price of } \\
\text { metal }\end{array}$ & $\$ / \mathrm{oz}$. & 1520 \\
\hline Selling cost of metal & $\$ / \mathrm{oz}$. & 1.7 \\
\hline Processing cost & $\$ / \mathrm{mt}$ & 9.03 \\
\hline Mining Cost & $\$ / \mathrm{mt}$ & 1.77 \\
\hline Slope & Degrees & 45 \\
\hline
\end{tabular}


Table 7 reports the estimates from the ultimate pit calculation. For proven reserves, all the blocks from the measured resource class which can be mined provided they respected economic and technical constraints, are classified as proven reserves and the indicated resources which can be mined while also obeying these constraints, are classified as probable reserves. The recoverable reserve estimates show proven reserves of $0.6303 \mathrm{~g} / \mathrm{mt}$ and probable reserves of $0.5442 \mathrm{~g} / \mathrm{mt}$.

Table 71 Grades and tonnages calculated from the reserves

\begin{tabular}{|c|c|c|c|}
\hline Reserve & $\begin{array}{c}\text { Average of } \\
\text { Grade (g/mt) }\end{array}$ & $\begin{array}{c}\text { Sum of } \\
\text { Tonnage } \\
\text { (Mmt) }\end{array}$ & $\begin{array}{c}\text { Sum of Metal } \\
\text { Content (Koz.) Au }\end{array}$ \\
\hline Proven & 0.6303 & 256.0 & $5,187.4$ \\
\hline Probable & 0.5442 & 400.6 & $7,009.2$ \\
\hline Grand Total & $\mathbf{0 . 5 7 7 8}$ & $\mathbf{6 5 6 . 6}$ & $\mathbf{1 2 , 1 9 6 . 6}$ \\
\hline
\end{tabular}

Recoverable reserves tonnages and gold metal content each represent about $37 \%$ of the whole resource model, and because of uncertainty being captured in the resource model, any discrepancies in the tonnages and metal content can be accounted for. Average grade of recoverable reserves of $0.5778 \mathrm{~g} / \mathrm{mt}$ also falls within the uncertainty margins of the resource model.

The mine value chain from mineral resource estimation, resource classification to reserve estimation is completed; the estimation, classification and reserve criteria are limited to the Plurigaussian simulation method, the relative conditional variance and maximum flow algorithm respectively as they enabled us to understand our resource model better. 


\section{Conclusion and recommendation for future work}

\subsection{Conclusion}

Mineral evaluation is key for the success of any mining project. This thesis evaluated spatial variability of grades within rock-types because this relationship is important in resource modeling, especially in heterogeneous deposits are a common phenomenon in most mineral deposits. Also, uncertainty of grades, tonnages and metal content is presented in this thesis because it provides a tool to curb risks that are inherent with mine planning and production due errors in resource modeling. Capturing both spatial variability and uncertainty in resource modeling is important in the decision making process for economic viability and therefore should be understood before mining commences. Because of the complexity of dealing with regionalized variables of different nature that are often crosscorrelated, such as grades (continuous variable) and rock-type (categorical variable), a joint simulation of grades and rock-types is proposed through simulating Gaussian Random Variables. In this method, Pluri-Gaussian geostatistical simulation algorithm is used to jointly simulate rock-types and grades, where the variograms and cross variograms parameters of the Gaussian random fields are iteratively optimized through trial and error fitting of the aforementioned variograms a with coregionalization model. The realizations generated from the joint simulation are then used for resource classification and reserve calculations providing a realistic mine plan scenario. The benefits of using this approach compared to deterministic methods of rock-type and grades modeling is that their spatial dependence and correlations can be determined, accounting for grade changes along boundaries of rock-types; while reducing the compounded errors of handling multiple simulations separately per variable. Another benefit is multiple realizations generated for both rock-types and grades provide joint uncertainty in the estimation process.

A good fitting of indicator and cross-variograms from the results indicate a reliable model which implies the simulation parameters inputs reproduce the actual dataset fairly. The coregionalized model also indicates presence of spatial dependency and auto-correlation between grades and rock-types. The generated multiple simulations provide an uncertainty 
to the estimates; the average grade varies from 0.4158 to $0.6479 \mathrm{~g} / \mathrm{mt}$ at an average grade of $0.5107 \mathrm{~g} / \mathrm{mt}$ of composite gold. The resource classification estimates are well within this range indicating that true grade estimates also fall within this range. Recoverable reserves calculations report almost 656 million metric tonnes of ore at an average grade of 0.5778 $\mathrm{g} / \mathrm{mt}$. The goals and objectives of using a joint simulation of grades and rock-types are achieved.

\subsection{Recommendations for future work}

The joint simulation of grades and rock-type uses the Pluri-Gaussian model for estimating grades and conditional simulation for uncertainty. The inadequacy in the proposed method in this thesis, is the challenge of selecting threshold values in the Pluri-Gaussian model for the truncation rule, especially when the number of rock-types increases and therefore also their Gaussian Random Fields. Another limitation in our model is its dependence on variogram analysis, which is limited in capturing geological domains with curvilinear shapes. Multi-point geostatistical tools can alleviate some of the limitations because the complex geological features are captured in the training image before further analysis. Comparative analysis with a deterministic model could also add some insight on how the proposed method performs. 


\section{Reference List}

1. Armstrong, M., Galli, A., Beucher, H., Loc'h, G., Renard, D., Doligez, B., ... \& Geffroy, F. (2011). Plurigaussian simulations in geosciences. Springer Science \& Business Media.

2. Betzhold, J., \& Roth, C. (2000). Characterizing the mineralogical variability of a Chilean copper deposit using plurigaussian simulations. Journal of the Southern African Institute of Mining and Metallurgy, 100(2), 111-119.

3. Chatterjee, S., Sethi, M. R., \& Asad, M. W. A. (2016). Production phase and ultimate pit limit design under commodity price uncertainty. European Journal of Operational Research, 248(2), 658-667.

4. Chiles, J. P., \& Delfiner, P. I. E. R. R. E. (1999). Modeling spatial uncertainty. Geostatistics, Wiley series in probability and statistics.

5. Deutsch, C. V., \& Journel, A. G. (1998). GSLib. Geostatistical software library and user's guide, 369.

6. Deutsch, C. V., Leuangthong, O., \& Ortiz, J. M. (2007). Case for geometric criteria in resources and reserves classification. TRANSACTIONS-SOCIETY FOR MINING METALLURGY AND EXPLORATION INCORPORATED, 322, 1.

7. Dohm, C. (2005). Quantifiable mineral resource classification: A logical approach. In Geostatistics Banff 2004 (pp. 333-342). Springer, Dordrecht.

8. Dowd, P. A., Pardo-Igúzquiza, E., \& Xu, C. (2003). Plurigau: a computer program for simulating spatial facies using the truncated plurigaussian method. Computers \& geosciences, 29(2), 123-141.

9. Dominy, S. C., Cuffley, B. W., McCarthy, P. L., Thomas, O. K., \& Hill, R. L. (2004). The challenges of evaluating and exploiting gold-quartz reefs in the Central Victorian Goldfield, Australia. In Proceedings New Leaders Conference 2004 (pp. 121-141).

10. Dominy, S. C., Noppé, M. A., \& Annels, A. E. (2002). Errors and uncertainty in mineral resource and ore reserve estimation: The importance of getting it right. Exploration and Mining Geology, 11(1-4), 77-98. 
11. Ebert, S., Miller, L., Petsel, S., Dodd, S., \& Kowalczyk, P. (2000). Geology, mineralization, and exploration at the Donlin Creek project, southwestern Alaska. The Tintina Gold Belt: Concepts, Exploration and Discoveries, British Columbia and Yukon Chamber of Mines, Special, 2, 99-114.

12. Emery, X. (2008). A turning bands program for conditional co-simulation of crosscorrelated Gaussian random fields. Computers \& Geosciences, 34(12), 1850-1862.

13. Emery, X. (2007). Simulation of geological domains using the plurigaussian model: new developments and computer programs. Computers \& Geosciences, 33(9), 1189-1201.

14. Emery, X., \& Lantuéjoul, C. (2006). Tbsim: A computer program for conditional simulation of three-dimensional gaussian random fields via the turning bands method. Computers \& Geosciences, 32(10), 1615-1628.

15. Emery, X., Ortiz, J. M., \& Rodríguez, J. J. (2006). Quantifying uncertainty in mineral resources by use of classification schemes and conditional simulations. Mathematical geology, 38(4), 445-464.

16. Emery, X., \& Silva, D. A. (2009). Conditional co-simulation of continuous and categorical variables for geostatistical applications. Computers \& Geosciences, 35(6), 1234-1246.

17. Goodfellow, R., Consuegra, F. A., Dimitrakopoulos, R., \& Lloyd, T. (2012). Quantifying multi-element and volumetric uncertainty, Coleman McCreedy deposit, Ontario, Canada. Computers \& geosciences, 42, 71-78.

18. Goovaerts, P. (1997). Geostatistics for natural resources evaluation. Oxford University Press on Demand.

19. Guardiano, Felipe B., and R. Mohan Srivastava. "Multivariate geostatistics: beyond bivariate moments." In Geostatistics Troia'92, pp. 133-144. Springer, Dordrecht, 1993.

20. Hart, C. J., McCoy, D. T., Goldfarb, R. J., Smith, M., Roberts, P., Hulstein, R., ... \& Bundtzen, T. K. (2002). Geology, exploration, and discovery in the Tintina Gold Province, Alaska and Yukon. SPECIAL PUBLICATION-SOCIETY OF ECONOMIC GEOLOGISTS, 9, 241-274. 
21. Hochbaum, D. S. (2001). A new—old algorithm for minimum-cut and maximumflow in closure graphs. Networks: An International Journal, 37(4), 171-193.

22. Jones, P., Douglas, I., \& Jewbali, A. (2013). Modeling combined geological and grade uncertainty: application of multiple-point simulation at the Apensu gold deposit, Ghana. Mathematical Geosciences, 45(8), 949-965.

23. Journel, A. G. (2003). Multiple-point geostatistics: a state of the art. Unpublished Stanford Center for Reservoir Forecasting paper.

24. Journel, A. G., \& Huijbregts, C. J. (1978). Mining geostatistics (Vol. 600). London: Academic press.

25. Kim, H. M., Mallick, B. K., \& Holmes, C. C. (2005). Analyzing nonstationary spatial data using piecewise Gaussian processes. Journal of the American Statistical Association, 100(470), 653-668.

26. Lang, J. R. (2000). An exploration model for intrusion-related gold systems. Soc. Econ. Geol. Newsletter, 40, 6-15.

27. Lantuéjoul, C. (2002). Geostatistical simulation: models and algorithms. Springer Science \& Business Media.

28. Lantuéjoul, C., \& Desassis, N. (2012, June). Simulation of a Gaussian random vector: a propagative version of the Gibbs sampler. In The 9th international geostatistics congress (pp. 174-181).

29. Liu, Y. (2006). Using the Snesim program for multiple-point statistical simulation. Computers \& Geosciences, 32(10), 1544-1563.

30. Mackenzie, D. H., \& Wilson, G. I. (2001). Geological interpretation and geological modelling. Mineral resource and ore reserve estimation-the AusIMM guide to good practice. The Australasian Institute of Mining and Metallurgy, Melbourne, 111-118.

31. Maleki, M., \& Emery, X. (2015). Joint simulation of grade and rock type in a stratabound copper deposit. Mathematical Geosciences, 47(4), 471-495.

32. Marcotte, D., \& Caron, J. (2013). Ultimate open pit stochastic optimization. Computers \& Geosciences, 51, 238-246. 
33. Montoya, C., Emery, X., Rubio, E., \& Wiertz, J. (2012). Multivariate resource modelling for assessing uncertainty in mine design and mine planning. Journal of the Southern African Institute of Mining and Metallurgy, 112(5), 353-363.

34. Ortiz, X. (2006). Geostatistical estimation of mineral resources with soft geological boundaries: a comparative study. Journal of the Southern African Institute of Mining and Metallurgy, 106(8), 577-584.

35. Osterholt, V., \& Dimitrakopoulos, R. (2007). Simulation of wireframes and geometric features with multiple-point techniques: application at Yandi iron ore deposit. Orebody modelling and strategic mine planning, 2nd edn. AusIMM, Spectrum Series, 14, 95-124.

36. Paithankar, A., \& Chatterjee, S. (2018). Grade and tonnage uncertainty analysis of an African copper deposit using multiple-point geostatistics and sequential Gaussian simulation. Natural Resources Research, 27(4), 419-436.

37. Pyrcz, M. J., \& Deutsch, C. V. (2014). Geostatistical reservoir modeling. Oxford university press.

38. Rossi, M. E., \& Deutsch, C. V. (2013). Mineral resource estimation. Springer Science \& Business Media.

39. Sagar, B. D., Cheng, Q., \& Agterberg, F. (Eds.). (2018). Handbook of Mathematical Geosciences: Fifty Years of IAMG. Springer.

40. Silva, D. S. F., \& Boisvert, J. B. (2014). Mineral resource classification: a comparison of new and existing techniques. Journal of the Southern African Institute of Mining and Metallurgy, 114(3), 265-273.

41. Silva, D. S., \& Deutsch, C. V. (2017). Multiple imputation framework for data assignment in truncated pluri-Gaussian simulation. Stochastic environmental research and risk assessment, 31(9), 2251-2263.

42. Sinclair, A. J., \& Garston, H. Blackwell, 2002. Applied Mineral Inventory Estimation, 284-299.

43. Snowden, D. V. (2001). Practical interpretation of mineral resource and ore reserve classification guidelines. Mineral Resource and Ore Reserve Estimation-The AusIMM Guide to Good Practice, 643-652. 
44. Sojdehee, Mona, Iraj Rasa, Nima Nezafati, Mansour Vosoughi Abedini, Nasser Madani, and Ehsan Zeinedini. "Probabilistic modeling of mineralized zones in Daralu copper deposit (SE Iran) using sequential indicator simulation." Arabian Journal of Geosciences 8, no. 10 (2015): 8449-8459.

45. Tahmasebi, P. (2018). Multiple point statistics: a review. In Handbook of mathematical geosciences (pp. 613-643). Springer, Cham.

46. Templeton, G. F. (2011). A two-step approach for transforming continuous variables to normal: implications and recommendations for IS research. Communications of the Association for Information Systems, 28(1), 4.

47. Wackernagel, H. (2003). Multivariate geostatistics: an introduction with applications. Springer Science \& Business Media.

48. Yunsel, T. Y., \& Ersoy, A. (2011). Geological modeling of gold deposit based on grade domaining using plurigaussian simulation technique. Natural resources research, 20(4), 231-249. 